\title{
Reference-dependent Preferences and the Transmission of Monetary Policy*
}

\author{
Edoardo Gaffeo ${ }^{\dagger} \quad$ Ivan Petrella $a^{\ddagger}$ Damjan Pfajfar§ ${ }^{\S}$ Emiliano Santoro
}

October 6, 2010

\begin{abstract}
This paper proposes a novel explanation of the vast empirical evidence showing that output and prices react asymmetrically to monetary policy innovations over contractions and expansions in the business cycle. We use VAR techniques to show that monetary policy exerts stronger effects on the U.S. GDP during contractionary phases, as compared to expansionary ones. As to prices, their response is not statistically different across different cyclical stages. We show that these facts are consistent with a New Neoclassical Synthesis model based on the assumption that households' utility partly depends on deviations of their consumption from a reference level below which aversion to loss is displayed. In line with the theory developed by Kahneman and Tversky (1979), losses in consumption utility loom larger than gains. This implies state-dependent degrees of real rigidity and elasticity of intertemporal substitution in consumption that generate competing effects on the responses of output and inflation following a monetary innovation. The key predictions of the model are in line with the data. We then explore the state-dependent trade-off between inflation and output stabilization that naturally arises in this context. Greater elasticity of inflation to real activity during expansionary stages of the cycle promotes a stronger degree of policy activism in the response to the expected rate of inflation under discretion, compared to what is otherwise prescribed during contractions.
\end{abstract}

JEL: E32; E52; D03; D11.

Keywords: Reference-dependent Preferences, Asymmetry, Monetary policy.

${ }^{*}$ We would like to thank Patricio Dalton, Jordi Galí, Boyan Jovanovic, Eric Leeper, Gert Peersman, Harald Uhlig and Pietro Veronesi for helpful comments and suggestions, as well as Tao Zha for sharing his codes. We would also like to thank participants at the 2010 ASSA Meetings (Atlanta), the 2010 CEF Conference (London) and the 2010 MMF Conference (Limassol, Cyprus). We also thank Janos Zsiros for his research assistance. All remaining errors are our own.

${ }^{\dagger}$ Department of Economics, University of Trento, Via Inama 5, 40138, Trento, Italy. E-mail: edoardo.gaffeo@unitn.it.

${ }^{\ddagger}$ Center for Economic Studies, Faculty of Business \& Economics, Katholieke Universiteit Leuven, Naamsestraat 69, 3000 Leuven, Belgium. E-mail: Ivan.Petrella@econ.kuleuven.be.

${ }^{\S}$ EBC, CentER, Department of Economics, Faculty of Economics and Business Administration, P.O. Box 90153, NL-5000 LE Tilburg, Netherlands. E-mail: D.Pfajfar@uvt.nl.

ITEMQ, Catholic University of Milan and Department of Economics, University of Copenhagen. Address: Via Necchi 5, 20123 Milan, Italy. E-mail: emiliano.santoro@unicatt.it. 


\section{Introduction}

Since the seminal work by Mitchell (1927), considerable effort has been devoted to the study of asymmetries in macroeconomic time series. Graham (1930), Keynes (1936) and Friedman and Schwartz (1963) have then stimulated a vast debate on the asymmetric effects of monetary policy. Widespread empirical evidence has been produced in support of the view that monetary policy exerts asymmetric effects on output and prices with respect to the economic conditions as well as the size and direction of the policy action. ${ }^{1}$ Such effects have important implications not only for the way we think about the macroeconomy, but also for the conduct of economic policy.

In this paper we focus on asymmetries in the transmission of monetary policy over contractionary and expansionary phases of the business cycle. Contractions (expansions) are intended as periods in which the cycle moves from its peak (trough) to the trough (peak). In this respect, two major regularities have emerged (see, e.g., Weise, 1999). On the one hand, monetary policy innovations have greater impact on output during negative stages of the cycles. On the other hand, changes in the monetary policy stance exert stronger effects on prices during expansionary phases. These facts motivate our study. We put forward a novel potential explanation of the cyclical asymmetries in the transmission of monetary policy, based on households displaying reference-dependent preferences in consumption. We show how embedding prospect theory (Kahneman and Tversky, 1979) in a popular macroeconomic framework can robustly account for the asymmetric effects of monetary policy on real activity and prices.

Reference-dependent preferences have received strong attention in the literature on asset pricing. Benartzi and Thaler (1995) and Barberis, Huang, and Santos (2001) have successfully employed prospect theory to explain the behavior of asset returns and resolve a number of quantitative asset pricing puzzles. A key feature of the model of Barberis, Huang, and Santos (2001) is that households care about gains and losses in financial wealth. By contrast, Koszegi and Rabin (2009) assume that households care about gains and losses in consumption. This assumption is empirically supported by Yogo (2008) and Rosenblatt-Wisch (2008).

The novelty of this paper is to embed reference-dependent utility in a dynamic general equilibrium framework. We set aside asset pricing implications and focus on the transmission of monetary policy on output and inflation. Our modeling strategy consists of assuming that consumers' utility partly depends on the deviation of their current consumption from the previous period's average consumption in the economy, which represents the habit reference level below which loss-aversion is displayed. In line with the theory developed by Kahneman and Tversky (1979) and Tversky and Kahneman (1991), losses in consumption utility resonate more than gains.

Two key mechanisms are identified. First, during contractions changes in the real rate of interest exert stronger impact on output through an increase in the elasticity of intertemporal

\footnotetext{
${ }^{1}$ Three main regularities have emerged: (i) money does affect output strongly when monetary policy is restrictive and raises inflation when it is expansive; (ii) the effects of money on output is greater during the contractionary phases of business cycles and their impact on inflation is greater during expansionary phases; (iii) if prices are sticky, then only negative shocks affect output. Here are some noteworthy contributions: Falk (1986), Cover (1992), Thoma (1994), Karras (1996), Acemoglu and Scott (1997), Weise (1999), Senda (2001), Ravn and Sola (2004), Peersman and Smets (2005), Lo and Piger (2005).
} 
substitution between current and future consumption. This property of the elasticity of intertemporal substitution has been widely explored in the literature on asset pricing (see, e.g., Yogo, 2008). Second, accounting for reference-dependent preferences in a general equilibrium setting implies a state-dependent marginal rate of substitution between consumption and leisure that can be related to firms' real marginal cost, so that equilibrium in the labor market holds. As a direct implication, the pass-through of real activity to prices depends on the level of consumption relative to its reference level and is lower during contractionary states as opposed to expansionary ones. Both features of the model are compatible with output being more adversely affected by monetary policy innovations during contractionary phases. Concurrently, inflation responses to monetary innovations are somewhat insulated by the higher responsiveness of real activity during negative growth cycles through an increased degree of real rigidity in the labor market.

We explore the state-dependent trade-off that naturally arises in this context. Optimal policy under discretion imposes a stronger degree of reactiveness to the expected rate of inflation in the expansionary state as compared to the contractionary one. Consequently, in the expansionary state monetary policy can reach a policy frontier which is otherwise unattainable under the contractionary one. On the one hand, assuming an aggressive monetary stance on inflation during contractions, i.e. a policy that aims at completely offsetting fluctuations in inflation, incurs into relatively higher costs in terms of output volatility. On the other hand, attaching increasing importance to output volatility gradually leads to similar costs in terms of inflation volatility across different states. Most importantly, reducing inflation variability by the same amount and from the same level in the two cyclical stages entails higher costs in terms of output variability during negative growth cycles.

It is important to recall that the macroeconomic literature has proposed a variety of mechanisms acting from both the supply and the demand side of the economy and capable to account for different types of asymmetry. ${ }^{2}$ Among others, Lo and Piger (2005) and Peersman and Smets (2005) suggest that the balance-sheet channel is consistent with larger effects of monetary policy on output during unfavorable growth states. However, this mechanism implies an analogous amplification (attenuation) of monetary policy innovations on both prices and real activity during contractionary (expansionary) phases, thus contradicting the empirical evidence. Different potential factors have also been proposed to account for other sources of asymmetry in the monetary transmission, such as non-linearities in investment (Bertola and Caballero, 1994), patterns of entry and exit from a given market under uncertainty about profit perspectives (Dixit, 1989), nominal rigidities in the labor and goods market (Ball and Mankiw, 1995), learning and information aggregation (Chalkley and Lee, 1998), convex aggregate supply (Devereux and Siu, 2007). ${ }^{3}$ However, a mechanism capable to account for the joint reaction of output and prices to a monetary policy innovation over different stages of the business cycle still has to emerge. We provide an alternative based on behavioral mechanisms that have found wide empirical and experimental support in the literature (Thaler, Tversky, Kahneman, and Schwartz, 1997).

The remainder of the paper is laid out as follows: Section 2 reports some empirical evidence

\footnotetext{
${ }^{2}$ For a survey of these approaches see Dufrenot, Mignon, and Peguin-Feissolle (2004).

${ }^{3}$ See Florio (2004) for a review of the literature.
} 
from a reduced form state-dependent VAR on the cyclical transmission of monetary policy; Section 3 details the theoretical framework we propose to account for these facts; Section 4 details the qualitative and quantitative features of the framework under scrutiny and provides intuition on the key mechanisms generating asymmetry in the responses of output and prices over different cyclical phases; Section 5 discusses the main policy implications of allowing for loss-averse preferences over consumption in our general equilibrium setting; the last section concludes.

\section{Empirical Evidence}

McKay and Reis (2008) have recently revived the interest in asymmetric fluctuations over different stages of the cycle. These are to be intended as phases of expansion and contraction in economic activity and are referred to as "growth cycles", in contrast with the "classical cycles" (Zarnowitz, 1992). The aim of this section is to document the effects of monetary policy on output and prices over positive and negative growth cycles. Two main results are highlighted: (i) first, the response of output is greater during contractionary phases and significantly smaller during expansionary ones; (ii) second, despite the amplification of output responses during negative growth cycles, prices are invariantly affected by a monetary policy innovation over different stages of the cycle. Asymmetries in the responses of either output or prices (primarily the former) to monetary policy innovations have widely been documented in the existing literature, although the analysis of their joint behavior has been somewhat disregarded. ${ }^{4}$

Since Bernanke and Blinder (1992) and Sims (1992), it has become common practice to implement vector autoregression (VAR) methods to identify and measure the effects of monetary policy innovations on macroeconomic variables. The monetary policy shock is identified as the unforecasted innovation of the policy instrument (for a survey, see Christiano et al., 1999). We follow this literature and employ a piecewise-linear structural VAR, distinguishing between contractionary and expansionary phases of the business cycle. We estimate the following monthly VAR model for the U.S. economy:

$$
Y_{t}=A(L) Y_{t-1}+\left[B(L) Y_{t-1}\right] \mathcal{I}+\varepsilon_{t}^{Y},
$$

where $Y_{t}$ is a vector of endogenous variables, $\varepsilon_{t}^{Y}$ is a vector of error terms that are assumed to be white noise and $\mathcal{I}=0$ when the economy is expanding, while $\mathcal{I}=1$ when the economy is in a contractionary phase of the cycle. We characterize contractions (expansions) as periods in which the output gap moves its peak (trough) to the trough (peak). The vector $Y_{t}$ includes the industrial production index (IPI), the consumer price index (CPI), commodities prices and the federal funds rate. All variables but the policy rate are in natural logarithms. ${ }^{5}$

A first problem in this type of empirical investigation relates to the determination of an indicator of contractions/expansions. We consider the month-to-month rate of growth of the CBO output gap series, i.e. the percentage deviation of real GDP from the Congressional Budget Office potential output. To identify growth cycles, we apply a four months one-sided MA filter

\footnotetext{
${ }^{4}$ Weise (1999) is a noteworthy exception.

${ }^{5}$ Data have been collected from the St. Louis Fed Economic Database, FRED ${ }^{\circledR}$.
} 
to the output gap series, so as to avoid the inclusion of those switches that do not last more than a quarter. ${ }^{6}$ Figure 1 reports the contraction bands consistent with our approach against the NBER recession bands and the output-gap series. Clearly, all NBER recession episodes fall within the contractionary phases implied by the output gap indicator.

\section{Insert Figure 1 here}

The VAR features a constant, a time trend and six lags, and is estimated over the time period 1955:M1-2008:M12. ${ }^{7}$ We generate impulse responses of the variables in $Y_{t}$ to a monetary policy shock, which is identified by imposing a triangular orthogonalization. Figure 2 displays impulse responses to a $1 \%$ interest rate shock under $\mathcal{I}=0$ and $\mathcal{I}=1 .{ }^{8}$ In both cases, a monetary policy shock exerts a clear contractionary effect on output. Overall, the response of prices is dominated by a pronounced price-puzzle effect. ${ }^{9}$ In spite of the similarity in the direction of the responses, some differences are clear. On the one hand, output is more adversely affected during contractionary phases. Specifically, the contractionary effect on output is more than twice as large as that appreciated in expansions. On the other hand, prices appear less responsive during contractionary episodes. Only a mild price-puzzle effect can be appreciated in this case, whereas the positive response is somewhat more sizeable during a positive growth cycle. However, the difference in price responses seems to be less evident than that observed for output.

\section{Insert Figure 2 here}

To assess the validity of the state-dependent VAR we run equation-by-equation F-tests in the reduced form VAR (1). This amounts to test the significance of the coefficient associated with the dummy variable. These F-tests yield p-values of 0.0514 for the industrial production index equation, 0.0016 for the price equation, 0.0028 for the commodity prices equation, and 0.0000 for the federal funds rate equation.

It must be stressed that the F-tests on the linear reduced-form VAR do not map on a oneto-one basis into a test on the corresponding impulse-response functions, as these are non-linear combinations of the estimated coefficients in the VAR. To assess the significance of cyclicaldependence in the impulse-response functions we construct a test on the maximum difference, in absolute value, between the impulse responses of each variable in the cycle-dependent VAR

\footnotetext{
${ }^{6}$ Taking a one-sided filter allows us to avoid simultaneity problems that potentially arise when data are splitted in accordance with the current state of the cycle. Results are robust to alternative indicator functions that select data based on previous period's cyclical phase. Our methodology is analogous to that employed by McKay and Reis (2008). They primarily rely on the algorithm developed by Bry and Boschan (1971) to date turning points in the cycle.

${ }^{7}$ The choice of this lag specification is consistent with the Schwarz information criterion (BIC). However, results are robust to alternative lag specifications.

${ }^{8}$ The figure also displays the $90 \%$ confidence bands obtained through the other percentile bootstrap method (Hall, 1992).

${ }^{9}$ As first noted by Sims (1992), empirical studies employing structural VARs generally detect positive and significant (on impact) responses of the price level to a monetary policy shock. Conventional dynamic general equilibrium frameworks cannot replicate such puzzling evidence. Sims (1992) and Bernanke, Boivin, and Eliasz (2005) suggest that this fact could be due to an omitted variables bias. By contrast, Barth and Ramey (2000) point to the cost channel as a possible "structural" explanation of this finding. In this section we focus on asymmetries in the response of prices to monetary innovations over different phases of the cycle, regardless of the direction of the response.
} 
and the linear VAR. ${ }^{10}$ This test complements the F-tests on the linear VAR equations. The p-values from this test are reported in Table 1.

\begin{tabular}{ccccc}
\hline \hline \multirow{2}{*}{ TABLE 1. Differences in impulse responses over different cyclical phases (p-values) } \\
\cline { 2 - 5 } Cyclical Phases & IPI & CPI & Commodity Prices & Fed Funds Rate \\
\hline Expansions & 0.0140 & 0.1660 & 0.0050 & 0.0040 \\
Contractions & 0.6600 & 0.8360 & 0.7650 & 0.0770 \\
\hline
\end{tabular}

We cannot reject the null hypothesis of a different response (with respect to the linear VAR) for contractions in the cycle and each of the variables included in the VAR, while we do reject the null hypothesis for expansionary episodes, for all variables but the CPI. These results support a statistically significant difference in output responses to a monetary shock between contractionary and expansionary episodes, with output being more sensitive to interest rate innovations during economic slowdowns. By contrast, prices are less responsive to contractions in aggregate demand during negative growth cycles. As remarked in Section 1, this evidence may be compatible with a number of mechanisms, such as a convex aggregate supply function. In the remainder of the paper we show how a model of reference-dependent preferences in consumption can provide a novel and alternative explanation of the observed asymmetries. Whereas this mechanism has drawn considerable attention in literature on asset pricing, which has been mainly aimed at reconciling the consumption-based CAPM with the empirical behavior of asset returns, little effort has been made to explore its relevance in the macroeconomic literature. Some applications to price setting (Heidhues and Koszegi, 2005) and consumption theory (Koszegi and Rabin, 2009) have recently been proposed. However, to the best of our knowledge, we provide the first contribution exploring the role of loss-aversion in consumption utility within a dynamic general equilibrium setting.

\section{A Model of Reference-dependent Consumption Choices}

This section sets out the structure of the model we put forward to explain the empirical evidence documented in the previous section. The supply side is populated by monopolistically competitive firms producing intermediate goods and a perfectly competitive sector of production that sells a composite of consumption goods. As to the demand side, there is a continuum of atomistic consumers, indexed by $i \in[0,1]$.

\subsection{Demand Side}

Households have preferences defined over leisure $\left(1-N_{i t}\right)$, consumption $\left(C_{i t}\right)$ and gains and losses in consumption relative to its reference level $\left(X_{i t}\right)$. They maximize the expected present

\footnotetext{
${ }^{10}$ We resort to simulation methods for inference. Using a bootstrap procedure, we calculate the distribution of the test statistics under the assumption that there is no cycle-dependence (for a similar test, see also Olivei and Tenreyro, 2007).
} 
discounted value of their utility:

$$
\mathcal{W}_{i t}=E_{t} \sum_{s=0}^{\infty} \beta^{s}\left[U\left(C_{i t+s}, X_{i t+s}\right)-\chi \frac{N_{i t+s}^{1+\eta}}{1+\eta}\right] ; \quad \chi>0,
$$

where $\beta$ is the intertemporal discount factor and $\eta$ is the inverse of the Frisch elasticity of labor supply. Following Koszegi and Rabin (2006) and Yogo (2008), we consider a general class of reference-dependent preferences: ${ }^{11}$

$$
U(C, X)=\alpha V(C)+(1-\alpha) \Lambda(V(C)-V(X)) ; \quad \alpha \in[0,1]
$$

where $V(C)$ is a neoclassical utility function: this is assumed to be continuously differentiable, strictly increasing, and concave for all $C>0 . \Lambda(\cdot)$ is a gain-loss function (Kahneman and Tversky, 1979), that is, utility derived from the deviation of consumption utility $V(C)$ from its reference level, $V(X) .{ }^{12}$ Preferences that depend on a reference level of consumption have psychological foundations in hedonic adaptation (see Frederick and Loewenstein, 1999). ${ }^{13}$

In line with Bowman, Minehart, and Rabin (1999), we assume that $\Lambda(\cdot)$ satisfies some properties. Specifically: (i) $\Lambda(Z)$ is continuous for all $Z^{\prime}$ s, twice differentiable for $Z \neq 0$ and $\Lambda(0)=0$; (ii) $\Lambda(Z)$ is strictly increasing; (iii) if $0<Z<Z^{\prime}$, then $\Lambda(Z)+\Lambda\left(-Z^{\prime}\right)<\Lambda(Z)+$ $\Lambda\left(-Z^{\prime}\right) ;\left(\right.$ iv) $\frac{\Lambda_{-}^{\prime}(0)}{\Lambda_{+}^{\prime}(0)}>1$, where $\Lambda_{+}^{\prime}(0)=\lim _{Z \rightarrow 0} \Lambda^{\prime}(|Z|)$ and $\Lambda_{-}^{\prime}(0)=\lim _{Z \rightarrow 0} \Lambda^{\prime}(-|Z|) ;(\mathrm{v})$ $\Lambda^{\prime \prime}(Z) \leq 0$ for $Z>0$ and $\Lambda^{\prime \prime}(Z) \geq 0$ for $Z<0$. Properties (i) and (ii) imply monotonicity, i.e. utility is strictly increasing in the magnitude of the gain. Loss-aversion, i.e. the impact of a loss is greater than that of an equally sized gain, is captured by (iii) for small stakes and (iv) for large stakes. These properties imply that when the representative consumer is in a bad state, she will become more sensitive to the relative consumption level than when she is in a good state. Finally, (v) is referred to as diminishing sensitivity, i.e. the marginal effect of a gain or a loss diminishes with its magnitude. To account for these properties we use an exponential gain-loss utility (Köbberling and Wakker, 2005):

$$
\Lambda(Z)=\left\{\begin{array}{cl}
\frac{1-\exp (-\theta Z)}{\theta} & \text { iff } Z \geq 0 \\
-\lambda \frac{\left[1-\exp \left(\frac{\theta}{\lambda} Z\right)\right]}{\theta} & \text { otherwise }
\end{array} ; \quad \theta \geq 0, \quad \lambda>1,\right.
$$

where $\theta$ determines the degree of diminishing sensitivity and $\lambda$ is a parameter that indexes the degree of loss-aversion. Note that for $\theta=0$ we obtain a linear gain-loss function. Otherwise, (4) retains the property to be smooth at the reference point. ${ }^{14}$

As to the reference consumption level, we assume that consumers evaluate the distance between consumption utility and a function of the average consumption in the previous period:

\footnotetext{
${ }^{11}$ For the time being, and without loss of generality, we describe reference-dependent preferences by reporting variables without subscripts.

${ }^{12}$ In the remainder we will assume, without loss of generality, logarithmic consumption utility.

${ }^{13}$ Koszegi and Rabin (2009) have envisaged a model of reference-dependent consumption choices. However, their focus is on the role of bad news about future consumption vs. good ones in the determination of current consumption choices. Other applications of this model, such as Yogo (2008), are mainly focused on asset pricing.

${ }^{14}$ This property is particularly useful in the perspective of linearizing the model economy.
} 
$X_{i t}=C_{t-1}^{\gamma}$, where $\gamma \in[0,1]$ indexes the importance of external habit formation. ${ }^{15}$ Therefore we follow Yogo (2008), embedding habit formation in a reference-dependent model. ${ }^{16}$ External habit formation in consumption is usually introduced to account for the empirical persistence in the consumption process (Smets and Wouters, 2007). Unlike internal habit formation, this mechanism implies that households fail to internalize the externality of their own consumption on the utility of other households.

To gain further intuition on the structure of reference-dependent preferences over consumption, Figure 3 plots (4) and its first order derivative for different values of $Z$ (x-axis) and $\lambda$ (we set $\theta=1$ ). As predicted by Kahneman and Tversky (1979), loss aversion reflects the widely observed behavior that agents are more sensitive to losses than gains, resulting in a gain-loss function that is steeper in the first case (see the left-hand panel of Figure 3).

\section{Insert Figure 3 here}

As to the intertemporal budget constraint, we assume that the $\mathrm{i}^{\text {th }}$ consumer, whose labor is remunerated at the real wage $W_{t}$, enters period $t$ with cash holdings $M_{i t}, B_{i t-1}$ one-period nominal bonds that pay $R_{t-1}$ gross interest $\left(1+i_{t-1}\right)$. Moreover, she receives the flow of dividends from a continuum of monopolistically competitive producers $\left(\Gamma_{i t}\right)$ and a lump sum transfer from the monetary authority $\left(T_{i t}\right)$ :

$$
P_{t} C_{i t}+B_{i t}+M_{i t+1} \leq M_{i t}+R_{t-1} B_{i t-1}+P_{t} W_{t} N_{i t}+\Gamma_{i t}+T_{i t}
$$

where $\Gamma_{i t}=\int_{0}^{1} \Pi_{i j t} d_{j}$.

Differentiating the Lagrangian with respect to individual consumption $\left(C_{i t}\right)$ and taking the consumption reference level as external to the $\mathrm{i}^{\text {th }}$ household returns the following Euler equation:

$$
E_{t}\left\{\frac{\left.U_{C}\left(C_{i t}, X_{i t}\right)\right|_{s_{i t}}}{\left.U_{C}\left(C_{i t+1}, X_{i t+1}\right)\right|_{s_{i t+1}}}\right\}=\beta E_{t}\left\{\frac{R_{t}}{1+\pi_{t+1}}\right\},
$$

where

$$
s_{i t}=\left\{\begin{array}{c}
A \text { iff } C_{i t} \geq X_{i t} \\
B \text { otherwise }
\end{array} \quad \forall t,\right.
$$

is an indicator function according to which the functional form of consumers' marginal utility depends on their gain-loss profile. The expected marginal rate of substitution between $C_{i t}$ and $N_{i t}$ reads as:

$$
\frac{\chi N_{i t}^{\eta}}{\left.U_{C}\left(C_{i t}, X_{i t}\right)\right|_{s_{i t}}}=W_{t}
$$

\footnotetext{
${ }^{15}$ Since the work of Abel (1990), external habit formation has become known as "catching up with the Joneses". We use the external habit definition in the spirit of Campbell and Cochrane (1999).

${ }^{16}$ The model offers a parsimonious framework to think about risk aversion and loss aversion. Risk aversion refers to the curvature of consumption utility, which determines the household's behavior for large gambles. Loss aversion refers to the magnitude of marginal utility for losses relative to gains, which determines the household's behavior for small gambles.
} 
Equations (6) and (8) are paramount to understand how cyclical asymmetries in transmission of monetary policy may arise in our model. Equation (6) regulates the intertemporal substitution between current and future consumption. A closer look at this relationship allows us to provide an intuition on the key mechanism at work in the dynamics of consumption. Households are more prone to bring consumption forward if they perceive that current and expected future consumption are both below the reference level (i.e., $s_{t}=s_{t+1}=B$ ). For $s_{t}=B$ the curvature of the reference-dependent utility function is lower than that observed under $s_{t}=A$, thus implying a higher elasticity of intertemporal substitution. Consequently, the marginal impact of the (real) interest rate on current consumption is also higher, relative to the alternative scenario, which implies that an unforecasted monetary policy innovation will have a greater impact on current consumption during negative growth cycles. Concurrently, equation (8) governs the intratemporal substitution between consumption and leisure. For a given $|V(C)-V(X)|$, the marginal rate of substitution between labor and consumption is higher when $V(C)<V(X)$. Under these circumstances households are more willing to cut on their leisure so as to increase consumption in the same period, compared to what happens when $V(C) \geq V(X)$. In a general equilibrium perspective, as labor is employed by a monopolistically competitive sector, we should expect a lower elasticity of firms' real marginal cost w.r.t. consumption (output). This translates into an attenuation of the impact of real activity on inflation when consumption is decreasing relative to its reference level, compared to what happens when it expands.

\subsection{Supply Side}

The final good is produced by perfectly competitive firms and requires the assembly of a continuum of intermediate goods, indexed by $j \in[0,1]$, via the following technology: $Y_{t}=$ $\left(\int_{0}^{1}\left(Y_{j t}\right)^{1-\frac{1}{\theta}} d j\right)^{\frac{\theta}{\theta-1}}$. Profit maximization leads to the demand function:

$$
Y_{j t}=\left(\frac{P_{j t}}{P_{t}}\right)^{-\theta} Y_{t} \quad \forall j
$$

where $P_{t}=\left(\int_{0}^{1}\left(P_{j t}\right)^{1-\theta} d j\right)^{\frac{1}{1-\theta}}$ is the price index consistent with the final good producer earning null profits. Total production equals aggregate consumption.

A continuum of firms produce intermediate goods. Each firm employs labor under a constant-returns-to scale technology:

$$
Y_{j t}=Z_{t} N_{j t}
$$

where $Z_{t}$ is a log-stationary total factor productivity shifter.

Following Christiano, Eichenbaum, and Evans (2005), we assume that firms set prices according to a variant of the Calvo (1983) specification. The probability that a firm can re-optimize its price in each period is $1-\omega$. Firms that cannot re-optimize simply follow a lagged-inflation indexation rule:

$$
P_{j t}=\Pi_{t}^{\vartheta} P_{j t-1} ; \quad \vartheta \in[0,1] .
$$

Optimizing firms maximize their expected stream of future profits, subject to (9) and (10). The 
cost minimization problem is specified as follows:

$$
\min _{N_{j t}} W_{t} N_{j t}+\Phi_{j t}\left[Y_{j t}-Z_{t} N_{j t}\right]
$$

The resulting real marginal cost is $R M C_{t}=W_{t} / Z_{t}$.

\subsection{The Monetary Authority}

The government sets the nominal rate of interest in accordance with a standard instrumental rule:

$$
\frac{R_{t}}{R}=\left(\frac{R_{t-1}}{R}\right)^{r_{R}}\left[\left(\frac{\Pi_{t}}{\Pi}\right)^{r_{\Pi}}\left(\frac{Y_{t}}{Y}\right)^{r_{Y}}\right]^{1-r_{R}} \exp \left(\mu_{t}\right)
$$

where $\Pi_{t}$ denotes the gross rate of inflation and $\mu_{t}$ is a trend-stationary monetary innovation. ${ }^{17}$ We assume that the government adheres to this rule via open market operations, which are financed by means of money transfers to the households, such that any deficits are equal to zero, i.e. $T_{t}=B_{t}-R_{t-1} B_{t-1}$.

Assuming a symmetric policy function to stabilize output and inflation represents a convenient way to close the model at this stage and focus on the effects of introducing referencedependent preferences into an otherwise standard framework. In Section 5 we focus on the monetary policy implications of this modeling assumption and formulate some policy prescriptions that account for the presence of reference-dependent preferences.

\subsection{Model Solution}

In the framework set out above households' utility is reference-dependent, i.e. its functional form depends on whether individual consumption is above or below the reference level (which is itself determined by aggregate past consumption). Furthermore, we assume that agents do not actually observe the reference level, $X_{t}$, but form beliefs on their relative position. In this respect, our assumption is similar in spirit to Veronesi (2004), who assumes that consumers do not observe their stock of habits, but possess a probability distribution on it. Veronesi (2004) introduces the concept of "beliefs-dependent" utility function (see also Geaneakoplos et al., 1989; Caplin and Leahy, 2001; Yariv, 2002) in a pure exchange economy, emphasizing the role of aversion to "state-uncertainty", which naturally arises in this context. In our case we consider beliefs-dependent preferences with neutrality to state-uncertainty. This allows us to partial out complications that may arise from aversion to state-uncertainty.

Given the intertemporal nature of households' maximization problem, we need to specify how agents' beliefs are formed, as these will determine the relevant branch of the referencedependent utility function. We assume that agents' beliefs about their position with respect to the stock of habits, i.e. on whether they are going to be above or below the reference consumption level in future periods, evolve as an invariant Markov chain. ${ }^{18}$ This assumption

\footnotetext{
${ }^{17}$ In the remainder, variables without time subscript denote the steady state value of their indexed counterparts.

${ }^{18}$ Considering an endogenous mechanism of beliefs switching is likely to alter the way monetary policy is transmitted and how the Central Bank should respond to smooth fluctuations in real activity and prices (see Davig and Leeper, 2008). Embedding such a mechanism in our model economy is an important development that
} 
allows us to overcome the endogeneity problem arising from the fact that at any given period $t$ agents evaluate their utility based on a state-dependent function and have to select a future consumption plan that depends on their reference consumption level, which is itself determined in the same period.

Within this setting we can cast the model in the form of a Markov Switching Rational Expectations (MSRE) model (see Farmer, Waggoner and Zha, 2008, 2009). ${ }^{19}$ To this end, we linearize the key equations in the neighborhood of $C / X=1$ and aggregate across individuals, assuming that in a symmetric equilibrium households make identical consumption-saving decisions. ${ }^{20}$ Conditional on their relative consumption in each period, consumers' beliefs evolve in accordance with the following transition matrix:

$$
Q=\left[\begin{array}{ll}
q_{A A} & q_{A B} \\
q_{B A} & q_{B B}
\end{array}\right]
$$

where $q_{A B}=\operatorname{Pr}\left(s_{t+1}=A \mid s_{t}=B\right)=1-q_{A A}$ and $q_{B A}=1-q_{B B}$. Equilibrium dynamics depends on agents' beliefs about their relative position with respect to the stock of habits. This implies that certain parameters can vary depending on the perceived "consumption state". As agents' beliefs evolve in accordance with (14), we have a standard MSRE model and it can be shown that the Minimal State Variable (MSV) solution is a Markov Switching VAR (see Farmer, Waggoner and Zha, 2008, 2009).

Importantly, dealing with reference-dependent habits necessarily implies that the parameters in the equilibrium system depend on states at time $t$ and $t-1$. Thus, as in Liu, Waggoner, and Zha (2009), we need to define a composite regime that accounts for all possible realizations of states in $t$ and $t-1$ :

$$
\xi_{t}=\left\{s_{t}, s_{t-1}\right\}=\{(A, A),(A, B),(B, A),(B, B)\}
$$

which implies four states, as reported in extensive form in Appendix A: an expansionary one, a contractionary one, and two turning points. In the remainder we pose stronger emphasis on the behavior of the model economy in expansions and contractions. To this end, we will refer to the expansionary state as that indexed by $\xi_{t}^{E}=\{A, A\}$, while the contractionary one is indicated

we leave for future research. At this stage of the analysis we are mainly interested in showing how the adoption of reference-dependent preferences in a model of external habit formation allows us to reproduce the asymmetric reaction of prices and quantities to a monetary innovation.

${ }^{19}$ In the quantitative analysis of Section 4.2 the model is solved under the assumption that the representative agent correctly observes in which regime she is in the current period. Therefore, uncertainty pertains solely to the states she is going to be in future periods. The dynamics of the model is one where agents weight the behavioral equations for the probabilities of regarding themselves in any of the "states" of the economy. Therefore, a measurement equation relates the model to the observables. This can be written as $Y_{t}=\sum_{i} \wp\left(s_{t}=i \mid I_{t-1}\right) Y_{i t}$, where $\wp\left(s_{t}=i \mid I_{t-1}\right)$ is the probability of being at state $i$ in period $t$ given the information set in the previous period. This probability is updated recursively based on the Bayes' rule (see, e.g., Liu, Waggoner and Zha, 2010). The probability associated with each state can be thought as a set of beliefs that the representative agent associates with each state at the moment of making her consumption choice, so that the utility function is effectively beliefs-dependent(see Veronesi, 2004 ).

${ }^{20}$ The difference between $\log$-variables under sticky prices and their linearized steady state is denoted by lower case letters. For further details, see Appendix A, where we report the linearized conditions for each of the four states taken separately. In Appendix B we report the model under the representation used to solve it through the generalized MSV approach developed by Farmer, Waggoner and Zha (2008, 2009), which is based on the canonical VAR representation of Sims (2002). 
by $\xi_{t}^{C}=\{B, B\}$.

\section{Asymmetries in the Transmission of Monetary Policy}

\subsection{Some Qualitative Insights}

As discussed in Section 3.1, embedding reference-dependent preferences over consumption in a general equilibrium framework induces two major changes in the key equations describing the dynamics of real activity and prices: (i) first, the elasticity of intertemporal substitution is state-dependent, being higher (lower) in contraction (expansion); (ii) second, a state-dependent marginal rate of substitution between consumption and leisure induces an attenuation of the impact of real activity on firms' pricing behavior during contractions. The first property has been widely explored by Yogo (2008). The second property is intimately connected with the role of reference-dependent preferences in a general equilibrium setting. A globally convex aggregate supply function can be envisaged in this context, which retains the property to be steeper (flatter) during expansionary (contractionary) episodes. Analogous functional forms have been explored in the literature on the Phillips curve, emphasizing the role of large shocks relative to small ones for firms' pricing behavior. ${ }^{21}$ In this respect, the existence of menu costs can rationalize a convex aggregate supply schedule. Nonetheless, it is interesting to notice how embedding reference-dependent preferences on consumption in a general equilibrium setting allows us to provide a microfoundation that emphasizes the role of state-dependent degrees of real rigidity in the labor market equilibrium allocation, rather than nominal rigidities.

It is useful to explore these intuitions further by inspecting the linearized relationships describing the behavior of demand and supply across different states. Specifically, we compare the responses of output and inflation to a monetary policy shock when agents "naively" expect the economy to permanently stay in either expansion or contraction. This amounts to impose, just for the time being, $q_{A A}=q_{B B}=1$. Liu, Waggoner, and Zha (2009) refer to the difference in the dynamic responses under the model with naive vs. sophisticated consumers as the "expectation effect." As explained by Davig and Leeper (2007), such expectation effect generally plays an important role in the presence of autocorrelated disturbances, which is not the case of the monetary policy innovation we envisage. To provide some useful analytical insight we also set $\gamma=0$, which corresponds to a case in which households consider the deviation of their consumption utility from the utility accruing from a constant consumption reference level. In this case we implicitly look at cyclical variations in output rather than at expansions/contractions in these cyclical movements. However, analogous implications carry over to the full model. We also assume an instrumental rule whereby the Central Bank responds solely to contemporaneous inflation and the output gap (i.e., $r_{R}=0$ ) and no indexation in the pricing process (i.e., $\vartheta=0$ ).

\footnotetext{
${ }^{21}$ See, e.g., Laxton, Rose, and Tambakis (1999) for a review of the literature and the analysis of the monetary policy implications of assuming a convex aggregate supply.
} 
The system of equations describing the model economy reads as:

$$
\begin{aligned}
y_{t} & =E_{t} y_{t+1}-\phi\left(\xi_{t}\right)\left(i_{t}-E_{t} \pi_{t+1}\right), \\
\pi_{t} & =\beta E_{t} \pi_{t+1}+\psi\left(\xi_{t}\right) y_{t}-\kappa(1+\eta) z_{t}, \\
i_{t} & =r_{\Pi} \pi_{t}+r_{Y} y_{t}+\mu_{t},
\end{aligned}
$$

where $\xi_{t}$ indexes the state-dependent parameters and $\kappa=(1-\omega \beta)(1-\omega)(\omega(1+\beta \vartheta))^{-1}$. The system (16)-(18) admits the following solution under rational expectations:

$$
\left[\begin{array}{c}
y_{t} \\
\pi_{t} \\
i_{t}
\end{array}\right]=\mathbf{A}\left(\xi_{t}\right)\left[\begin{array}{c}
z_{t} \\
\mu_{t}
\end{array}\right],
$$

where $\mathbf{A}\left(\xi_{t}\right)$ is a state-dependent $3 \times 2$ matrix of parameters that determines the marginal impact of the shocks on the vector of state and control variables. Let us now compare the response (on impact) of output and inflation to the monetary policy shock $\left(\mu_{t}\right)$ over expansions and contractions. As to output:

$$
\begin{aligned}
& a_{12}\left(\xi_{t}^{E}\right)=-\frac{1}{r_{Y}+\kappa r_{\Pi}(\eta+1+(1-\alpha) \theta)+1+(1-\alpha) \theta}, \\
& a_{12}\left(\xi_{t}^{C}\right)=-\frac{1}{r_{Y}+\kappa r_{\Pi}\left(\eta+1-(1-\alpha) \frac{\theta}{\lambda}\right)+1-(1-\alpha) \frac{\theta}{\lambda}},
\end{aligned}
$$

while, for inflation:

$$
\begin{aligned}
& a_{22}\left(\xi_{t}^{E}\right)=-\frac{\kappa(\eta+1+(1-\alpha) \theta)}{r_{Y}+\kappa r_{\Pi}(\eta+1+(1-\alpha) \theta)+1+(1-\alpha) \theta}, \\
& a_{22}\left(\xi_{t}^{C}\right)=-\frac{\kappa\left(\eta+1-(1-\alpha) \frac{\theta}{\lambda}\right)}{r_{Y}+\kappa r_{\Pi}\left(\eta+1-(1-\alpha) \frac{\theta}{\lambda}\right)+1-(1-\alpha) \frac{\theta}{\lambda}} .
\end{aligned}
$$

These results readily provide us with some implications about the response of output and inflation to a monetary innovation across the two states. These are summarized in the following propositions.

Proposition 1 In the model described by equations (16)-(18) under $q_{A A}=q_{B B}=1$ (i.e., naive agents) the absolute response of output to a monetary innovation is greater under $\xi_{t}^{C}$ than under $\xi_{t}^{E}$. The proof to this proposition is easily obtained by showing that

$$
\left|a_{12}\left(\xi_{t}^{C}\right)\right|>\left|a_{12}\left(\xi_{t}^{E}\right)\right|
$$

which is always true for $\lambda>-1$. Recall that $\lambda>1$ by definition.

Proposition 2 In the model described by equations (16)-(18) under $q_{A A}=q_{B B}=1$ (i.e., naive agents) the absolute response of inflation to a monetary innovation is greater under $\xi_{t}^{E}$ than under $\xi_{t}^{C}$ if and only if $r_{Y}>\eta$. It can also be shown that the response of inflation conditional to the output gap response in the contractionary state is lower than that appreciated in expansion, whenever agents display loss-averse preferences. To prove this statement, it is sufficient to prove 
that:

$$
\left|\frac{a_{22}\left(\xi_{t}^{C}\right)}{a_{12}\left(\xi_{t}^{C}\right)}\right|<\left|\frac{a_{22}\left(\xi_{t}^{E}\right)}{a_{12}\left(\xi_{t}^{E}\right)}\right|,
$$

which is always true for $\lambda>-1$.

First of all, note that imposing $\lambda=-1$ implies that $\Lambda(\cdot)$ is no longer reference-dependent, as its functional form is the same regardless of the value of $V(C)$ relative to $V(X)$. Under these circumstances $a_{12}\left(\xi_{t}^{C}\right)=a_{12}\left(\xi_{t}^{E}\right)$ and $a_{22}\left(\xi_{t}^{C}\right)=a_{22}\left(\xi_{t}^{E}\right)$. Indeed, the responses of output and inflation are also the same for $\alpha=1$, which amounts to ruling out reference-dependent preferences.

Assuming reference-dependent preferences implies state-dependent degrees of real rigidity and elasticity of intertemporal substitution in consumption that potentially generate competing effects on the responses of output and inflation following a monetary innovation. Specifically, the IS schedule displays a higher elasticity of intertemporal substitution in contractions as compared to expansions, as $\phi\left(\xi_{t}^{C}\right)>\phi\left(\xi_{t}^{E}\right)$. This result is in line with the analysis of Yogo (2008) and solely depends on the introduction of loss aversion in households' preferences (i.e., it holds as long as $\lambda>-1$, which is always true, as $\lambda>1$ by construction). As to the state-dependent NKPC, it is straightforward to show that $\psi\left(\xi_{t}^{C}\right)<\psi\left(\xi_{t}^{E}\right)$ in Equation (17), meaning that the elasticity of inflation to the output gap is lower in contractions. This inequality is nothing but (24), which shows that the conditional response of inflation to the monetary innovation is always lower in contractions. However, this may not be enough to generate an attenuation in the absolute response of inflation to a monetary innovation. To see why this is the case note that in contractions lower real rigidity in the NKPC is counteracted by a greater amplification in the response of output, as predicted by Proposition 1. Therefore, the overall impact of a monetary shock on inflation depends on the relative magnitude of these competing forces. We have shown that $\left|a_{22}\left(\xi_{t}^{C}\right)\right|<\left|a_{22}\left(\xi_{t}^{E}\right)\right|$ does not hold unless the systematic policy response to the output gap $\left(r_{Y}\right)$ is strong enough to overcome the amplification effect induced by the inverse of the Frisch elasticity of labour supply $(\eta)$. It must be stressed that, should the Central Bank be a pure inflation targeter (i.e., $\left.r_{Y}=0\right), r_{Y}>\eta$ is never attained. However, it is useful to note that for $r_{Y}>0$ this condition is not unlikely to hold, if we consider the values of $\eta$ that have generally been calibrated. Recall that $\eta$ measures the elasticity of the marginal disutility of labor with respect to hours worked. Rotemberg and Woodford (1998) report evidence of low values of this elasticity, generally between 0.25 and 0.4, while McCallum (2001) suggests values closer to the lower bound. Kimball and Shapiro (2008) estimate this elasticity to be equal to 1 , and stress that such a value is higher than most estimates previously obtained. According to Eusepi and Preston (2009) the elasticity is about $0.25 .^{22}$ In Section 4.2 we will see how considering the probability of switching between regimes as well as the full linearized model economy allows us to robustly obtain attenuation in inflation responses over contractionary phases of the cycle, despite the amplification of output responses.

To assess the amplification/attenuation effects induced by reference-dependent preferences

\footnotetext{
${ }^{22}$ Notice also that $\eta=0$, i.e., linear disutility of labor, would be consistent with the concept of "indivisible labor" which implicitly incorporates the extensive margin of labor adjustment in the baseline RBC setting (Hansen, 1985; Rogerson, 1988).
} 
on output and inflation over different cyclical phases it is useful to inspect the following ratios, for different values of $\lambda:^{23}$

$$
M_{y}=\frac{a_{12}\left(\xi_{t}^{C}\right)}{a_{12}\left(\xi_{t}^{E}\right)} ; \quad M_{\pi}=\frac{a_{22}\left(\xi_{t}^{C}\right)}{a_{22}\left(\xi_{t}^{E}\right)} ; \quad M_{\pi \mid y}=\frac{a_{22}\left(\xi_{t}^{C}\right) / a_{22}\left(\xi_{t}^{E}\right)}{a_{12}\left(\xi_{t}^{C}\right) / a_{12}\left(\xi_{t}^{E}\right)} .
$$

We set $r_{Y}=0.5, r_{\Pi}=1.5, \alpha=0.5, \theta=1, \kappa=0.09$. As to $\eta$, we consider three values, namely $0,0.5$ and 1 , so as to allow for $r_{Y} \lesseqgtr \eta$ and compare the extent of amplification/attenuation of inflation responses to the policy shock. Figure 4 reports numerical values for $M_{y}, M_{\pi}$ and $M_{\pi \mid y}$. The amplification induced by reference-dependent preferences on output responses in contraction monotonically declines in the level of $\lambda .{ }^{24}$ However, loss aversion induces substantial amplification of output responses in the contractionary state, with values of $\left|a_{12}\left(\xi_{t}^{C}\right)\right|$ that can be from $106 \%$ to $44 \%$ greater than $\left|a_{12}\left(\xi_{t}^{E}\right)\right|$, for $\lambda \in[1,5]$.

\section{Insert Figure 4 here}

As to inflation, for $\eta=0$ the attenuation effect experienced in contractionary phases increases in $\lambda$, ranging from $15 \%$ to $32 \%$ over the same interval for $\lambda$. For $\eta=1$, the multiplier decreases over the range of values for $\lambda$. Within this interval inflation responses are only slightly greater in contractions, with an amplification that ranges from $18 \%$ to $8 \%$. Note that the absolute magnitude of the amplification/attenuation effect on inflation responses for various parameter values and different cyclical phases is much lower compared to that induced on output responses by loss-aversion. As a result, inflation responses to policy innovations during negative growth cycles are somewhat insulated from the strong amplification in the response of real activity through reduced real rigidity in the labor market equilibrium. The third panel of Figure 4 also reports the ratio between the responses of inflation in contraction and expansion, conditional to the output responses. Clearly, as implied by Proposition 2, conditional inflation responses are always substantially stronger in expansion.

\subsection{Quantitative Analysis}

To quantify the differential impact of monetary policy over contractions and expansions we compute numerical solutions to the linearized model economy. To this end, we need to assign some parameter values. We calibrate the model at a quarterly frequency. We set $\beta=0.99$ and $\theta=1$. The inverse of the Frisch elasticity of labor supply $(\eta)$ is set to 0.25 , while $\chi$ is such that steady state consumption equals one. As to the weight of habit formation, $\gamma=0.9$. We do not have any direct empirical reference in the literature on dynamic general equilibrium models about the parameter indexing the degree of loss-aversion. We set it in accordance with

\footnotetext{
${ }^{23}$ It is also worth pointing out that envisaging different values of $\lambda$ for a given value of $\theta$ amounts to impose different degrees of diminishing sensitivity above and below the reference level. Specifically, $\theta\left(\xi_{t}^{C}\right)<\theta\left(\xi_{t}^{E}\right)$. This is in line with the strong form of loss aversion of Wakker and Tversky (1993), which implies $\Lambda^{\prime}(-Z)>\Lambda^{\prime}(Z)$, $\forall Z>0$. Such an assumption implies that $\Lambda(\cdot)$ is closer to linear for losses than gains, which is in line with the empirical findings, and is important to detect amplification/attenuation effects in the linearized economy. Otherwise, imposing the same $\theta$ over different states would not produce major asymmetries once we approximate the model up to a first order in the neighborhood of $Z=0$.

${ }^{24}$ To provide an intuition on why this happens it is useful to inspect Figure 3, where the curvature of the left-hand of $\Lambda(\cdot)$ diminishes in $\lambda$, coming close to zero for high values of this parameter.
} 
the value suggested by Tversky and Kahneman (1992), i.e. $\lambda=2.25$. Nominal rigidity is such that $\omega=0.66$ and $\vartheta=0.5$. As to the policy reaction function, we set $r_{R}=0.7, r_{Y}=0.5$ and $r_{\Pi}=1.5$. We assume a purely transitory monetary policy shock, with $\sigma^{\mu}=0.02$.

As to the transition matrix, $Q$, we calibrate it in line with the empirical evidence reported in Section 2. We use the CBO official output gap series and compute the average duration between the bottom of a recession and the top of an expansion. Reverse arguments apply to compute the average duration of contractionary phases. The probabilities of switching across states are then retrieved as the inverse of the duration of each phase: $q_{A B}=0.135$ and $q_{B A}=$ 0.163 , respectively. ${ }^{25}$ These values translate into a strong persistence of expansionary and contractionary states, whose probability is captured by the main diagonal elements of $Q$ : a direct implication is that the analysis pursued in Section 4.1, where $q_{A A}=q_{B B}=1$, should not be qualitatively affected by introducing a non-diagonal transition matrix, at least for a purely forward-looking economy.

We are now ready to assess the impact of a monetary policy contraction on output and inflation. Figure 5 reports the responses to a monetary policy shock. In each graph, the solid line corresponds to the model under the expansionary state, while the dashed line refers to the contractionary one. A note of caution is warranted at this point. The graphs are responses of the system to a monetary policy shock conditional on other shocks being set at time zero. It is a convention to report variables in log-deviation from their steady state level. As such, a contractionary monetary policy shock inevitably implies a negative output response under both regimes, and not just in the contractionary one. However, in a more general setting we could envisage a composition of shocks hitting the economy, so that the monetary shock alone is not enough to influence the realization of a certain state. Therefore, a rising rate of interest can cause a contraction in economic activity without this being in contrast with the specification of the model.

\section{Insert Figure 5 here}

It is clear how the response of output is stronger during contractionary phases as opposed to expansionary ones, a result in line with the analysis of Section 4.1, which confirms the robustness of the mechanism at work in generating asymmetric responses of real activity between positive and negative growth cycles. As to the response of inflation during contractions, this is insulated from the higher responsiveness of real activity: overall, we cannot appreciate much difference in inflation responses over different states. ${ }^{26}$ The model can qualitatively replicate the evidence presented in Section 2. The key mechanism works along the lines detailed above. On the one hand, when consumption is initially believed to lie below its reference level, the sensitivity of output to changes in the real rate of interest is higher, compared to the case of a perceived

\footnotetext{
${ }^{25}$ We also explore the responses to a monetary contraction under the assumption that agents naively believe that a given state will last forever. These results are available, upon request, from the authors. However, as explained above, a transitory policy innovation implies no major difference in the dynamic responses under the model with naive vs. sophisticated consumers.

${ }^{26}$ This result is robust to alternative values of $\eta$ relative to $r_{Y}$. For $r_{Y}>\eta$ we commonly observe a weak attenuation of inflation responses to monetary shocks taking place during contractions. Otherwise, we appreciate no major difference in the response of inflation between contractions and expansions for alternative parameterizations.
} 
"expanding" consumption path. On the other hand, the response of inflation is attenuated when consumers display loss aversion in consumption, as indicated by the shape of the marginal rate of substitution between consumption and leisure [Eq. (8)] and the resulting state-dependent NKPC.

\section{Implications for Monetary Policy}

Once it is recognized that monetary policy exerts an asymmetric impact on output and, to some extent, inflation, it is of obvious importance to explore how the policy maker should behave to properly account for these facts. To evaluate the policy implications of embedding reference-dependent preferences into a dynamic general equilibrium context it is useful to think about a scenario in which the monetary authority acts discretionally and takes the perceived expansionary and contractionary stages separately. ${ }^{27}$ This is done for two main reasons. First, from a practical viewpoint, working under discretion allows us to envisage a sequence of static optimization problems. In this perspective, the Central Bank does not need to consider the probability of switching across different states. Second, from an institutional viewpoint it is hard to think about a Central Bank that makes any strictly binding commitment on its future policy action (Clarida, Gali, and Gertler, 1999).

We employ a purely forward-looking system. Once again, this amounts to set $\gamma=\vartheta=0$, thus allowing for: (i) a gain-loss function in which deviations of consumption from a constant reference level $(X=1)$ are weighted; (ii) no indexation in price-setting. In each period the monetary authority chooses $y_{t}$ and $\pi_{t}$ to maximize

$$
L_{t}=-\frac{1}{2}\left[\varrho y_{t}^{2}+\pi_{t}^{2}\right]+F_{t},
$$

subject to

$$
\pi_{t}=\beta E_{t} \pi_{t+1}+\psi\left(\xi_{t}\right) y_{t}+u_{t},
$$

taking $F_{t}=-\frac{1}{2} E_{t} \sum_{i=1}^{\infty} \beta^{i}\left[\pi_{t+i}^{2}+\varrho y_{t+i}^{2}\right]$ as given and where $u_{t}$ is a stationary $\operatorname{AR}(1)$ exogenous cost shifter with autoregressive parameter $\rho^{u} .{ }^{28}$ This shock is included to account for a meaningful policy trade-off between inflation and output stabilization. The solution to this problem returns the well known relationship:

$$
y_{t}=-\frac{\psi\left(\xi_{t}\right)}{\varrho} \pi_{t}
$$

which means that whenever inflation is above the target the Central Bank should contract output below capacity (thus implementing a leaning against the wind policy). However, allowing for loss averse preferences determines state-dependent degrees of real rigidity, captured by $\psi\left(\xi_{t}\right)$,

\footnotetext{
${ }^{27}$ In the setup we envisage the Central Bank does not exert any control on which regime is in place at any given point in time. In this respect, policy interventions are only "modest" in their scope (see Leeper and Zha, 2003). By contrast, consumption regimes solely depend on agents' beliefs, which are assumed to evolve exogenously. As a direct consequence the architecture of the model economy is substantially insulated from the Lucas' critique.

${ }^{28}$ The welfare criterion expressed in (26) is widely used to capture the stabilization objective of the central bank over the target variables $\pi_{t}$ and $y_{t}$. However, under reference-dependent utility we could envisage a statedepenedent welfare criterion that mimics households' preferences.
} 
that alter the nature of the trade-off between output and inflation stabilization depending on the perceived deviation of consumption from its reference level:

$$
\begin{aligned}
& \psi\left(\xi_{t}^{E}\right)=\kappa(\eta+1+(1-\alpha) \theta), \\
& \psi\left(\xi_{t}^{C}\right)=\kappa\left(\eta+1-(1-\alpha) \frac{\theta}{\lambda}\right) .
\end{aligned}
$$

It is evident how, for a given level of above-the-target inflation, the Central Bank does not need to contract output in the contractionary state as much as it should do in the expansionary one. Recall that in the contractionary state the real interest rate has a much greater impact on real activity, while inducing only moderate effects on inflation. Within this setting we can derive the optimal state-dependent interest rate rule under discretion:

$$
i_{t}=r_{\Pi}\left(\xi_{t}\right) E_{t} \pi_{t+1},
$$

where

$$
\begin{aligned}
& r_{\Pi}\left(\xi_{t}^{E}\right)=1+\frac{\kappa\left(1-\rho^{u}\right)(\eta+1+(1-\alpha) \theta)}{\frac{\varrho \rho^{u}}{1+(1-\alpha) \theta}}, \\
& r_{\Pi}\left(\xi_{t}^{C}\right)=1+\frac{\kappa\left(1-\rho^{u}\right)\left(\eta+1-(1-\alpha) \frac{\theta}{\lambda}\right)}{\frac{\varrho \rho^{u}}{1-(1-\alpha) \frac{\theta}{\lambda}}}
\end{aligned}
$$

and it can be shown that

$$
r_{\Pi}\left(\xi_{t}^{E}\right)>r_{\Pi}\left(\xi_{t}^{C}\right) .
$$

Therefore, the optimal policy under discretion imposes a higher degree of reactiveness to the expected rate of inflation in the expansionary state as compared to the contractionary one.

A useful way to illustrate the trade-off between inflation and output stabilization implied by the model is to construct the corresponding efficient policy frontier. Combining the IS with the aggregate supply schedule and the optimal policy under discretion returns the locus of points that characterize how the unconditional variances of output and inflation vary with Central Bank preferences, as indexed by $\varrho$. Figure 6 portrays the efficient policy frontiers for the two alternative scenarios under the calibration considered in the previous section.

\section{Insert Figure 6 here}

The graph clearly shows that in the expansionary state monetary policy can reach a policy frontier which is instead infeasible under the contractionary one. During contractions an aggressive monetary stance on inflation, i.e. a policy that aims at completely offsetting fluctuations in inflation incurs into relatively higher costs in terms of output volatility. However, attaching increasing importance to output volatility gradually leads to similar costs in terms of inflation volatility across different states. A perhaps more important observation is that decreasing output variability by the same amount in contractions and expansions entails a lower increase in inflation volatility in the first case. This can be readily noticed by picking a point on both frontiers at the same level of $\sigma_{y}$, thus moving down along each locus so as to attain an analogous reduction in output variability: the relative increase in $\sigma_{\pi}$, which is measured on the 
$\mathrm{x}$-axis, is greater under expansions than contractions. Therefore, pursuing a decrease in output variability as a policy objective should be rather done during economic slowdowns, so has to exploit a lower pass-through from output to inflation and trigger lower pressures in terms of inflation volatility, provided that the Central Bank aims at remaining on the policy frontier.

\section{Concluding Remarks}

This paper provides a novel explanation of the vast empirical evidence showing that output and prices react asymmetrically to monetary policy innovations over contractionary and expansionary phases of the business cycle. We use a piecewise linear VAR to show that monetary policy has stronger effects on the U.S. GDP during contractions, as compared to expansions. As to prices, their response is not statistically different across different stages of the cycle.

These facts are consistent with a dynamic general equilibrium model featuring external habit formation in consumption in which we embed reference-dependent preferences: households' utility partly depends on deviations of their consumption from a reference level below which switching to different preferences takes place. In line with the theory developed by Kahneman and Tversky (1979) losses in consumption utility loom larger than gains. This implies statedependent degrees of real rigidity and elasticity of intertemporal substitution in consumption that generate competing effects on the responses of output and inflation following a monetary innovation. The model is solved by imposing that agents have imperfect observability of the stock of habits and their relative position with respect to this endogenous reference point. We also assume that agents' beliefs evolve as an invariant Markov chain, which allows us to deal with a Markov Switching Rational Expectations (MSRE) model (see Farmer, Waggoner and Zha, 2008, 2009). The qualitative and quantitative analyses return predictions that are in line with the empirical evidence. Output responses to a monetary contraction are greater in contractions as compared to expansions. Despite the amplification of output responses during negative growth cycles, inflation responses are insulated through lower real rigidity induced by reference-dependent preferences, so that we cannot detect major differences in inflation responses over different cyclical phases.

An obvious step is to explore the state-dependent trade-off between inflation and output stabilization that naturally arises in this context. Optimal policy under discretion imposes a higher degree of reactiveness to the expected rate of inflation in the expansionary state as compared to the contractionary one, the reason being that during contractions an aggressive monetary stance on inflation, i.e. a policy that aims at completely offsetting fluctuations in inflation, incurs into relatively higher costs in terms of output volatility.

To the best of our knowledge, this is the first application of reference-dependent preferences over consumption in a dynamic general equilibrium perspective. This modeling device has already proven to be a useful extension of the consumption-based asset pricing model (CAPM) in various studies (e.g., Barberis et al., 2001). Importantly, we show how loss aversion in consumption utility can also be useful at reconciling the otherwise standard DSGE workhorse with the widespread evidence on the asymmetric effects of monetary policy over different stages of the business cycle. 
It must be stressed that we have focused on a necessarily simplified model in which the mechanism of switching between different states follows an exogenous process. ${ }^{29}$ Within this setup we can provide a clear intuition of the key intertemporal and intratemporal mechanisms at work under reference-dependent utility in a general equilibrium framework, as well as their monetary policy implications. Allowing for an endogenous mechanism of switching should represent an interesting extension to this framework. As emphasized by Bernanke (2004), preemptive policy behavior might have lasting effects on expectation formation and the management of public beliefs would be a core part of the policy action. In turn, beliefs over the actual and future monetary policy stance should play an important role in propagating various shocks and inducing varying degrees of persistence in the dynamics of nominal and real variables (see Andolfatto and Gomme, 2003).

\footnotetext{
${ }^{29}$ Currently, computational limitations do not allow us to study the model under a fully endogeneized switching process. Clearly, imposing exogeneity in the evolution of agents' beliefs represents a assumption which should be relaxed in the future, possibly along the lines of Davig and Leeper (2008).
} 


\section{References}

Abel, A. B. (1990): "Asset Prices under Habit Formation and Catching Up with the Joneses," American Economic Review, 80(2), 38-42.

Acemoglu, D., and A. Scott (1997): "Asymmetric business cycles: Theory and time-series evidence," Journal of Monetary Economics, 40(3), 501-533.

Andolfatto, D., and P. Gomme (2003): "Monetary Policy Regimes and Beliefs," International Economic Review, 44(1), 1-30.

Ball, L., And N. G. Mankiw (1995): "Relative-Price Changes as Aggregate Supply Shocks," The Quarterly Journal of Economics, 110(1), 161-93.

Barberis, N., M. Huang, and T. Santos (2001): "Prospect Theory And Asset Prices," The Quarterly Journal of Economics, 116(1), 1-53.

Barth, M. J., And V. A. Ramey (2000): "The Cost Channel of Monetary Transmission," NBER Working Papers 7675, National Bureau of Economic Research, Inc.

Benartzi, S., and R. H. Thaler (1995): "Myopic Loss Aversion and the Equity Premium Puzzle," The Quarterly Journal of Economics, 110(1), 73-92.

Bernanke, B. (2004): The Logic of Monetary Policy, Remarks made before the National Economists Club. Board of Governors of the Federal Reserve System.

Bernanke, B., J. Boivin, and P. S. Eliasz (2005): "Measuring the Effects of Monetary Policy: A Factor-augmented Vector Autoregressive (FAVAR) Approach," The Quarterly Journal of Economics, 120(1), 387-422.

Bernanke, B. S., And A. S. Blinder (1992): "The Federal Funds Rate and the Channels of Monetary Transmission," American Economic Review, 82(4), 901-21.

Bertola, G., and R. J. Caballero (1994): "Irreversibility and Aggregate Investment," Review of Economic Studies, 61(2), 223-46.

Bowman, D., D. Minehart, and M. Rabin (1999): "Loss aversion in a consumption-savings model," Journal of Economic Behavior \& Organization, 38(2), 155-178.

Bry, G., And C. Boschan (1971): Cyclical Analysis of Time Series: Selected Procedures and Computer Programs, NBER Books. National Bureau of Economic Research, Inc.

Calvo, G. A. (1983): "Staggered prices in a utility-maximizing framework," Journal of Monetary Economics, 12(3), 383-398.

Campbell, J. Y., and J. Cochrane (1999): "Force of Habit: A Consumption-Based Explanation of Aggregate Stock Market Behavior," Journal of Political Economy, 107(2), 205-251.

Caplin, A., and J. Leahy (2001): "Psychological Expected Utility Theory And Anticipatory Feelings," The Quarterly Journal of Economics, 116(1), 55-79. 
Chalkley, M., and I. H. Lee (1998): "Learning and Asymmetric Business Cycles," Review of Economic Dynamics, 1(3), 623-645.

Christiano, L. J., M. Eichenbaum, and C. L. Evans (1999): "Monetary policy shocks: What have we learned and to what end?," in Handbook of Macroeconomics, ed. by J. B. Taylor, and M. Woodford, vol. 1 of Handbook of Macroeconomics, chap. 2, pp. 65-148. Elsevier.

(2005): "Nominal Rigidities and the Dynamic Effects of a Shock to Monetary Policy," Journal of Political Economy, 113(1), 1-45.

Clarida, R., J. Gali, and M. Gertler (1999): "The Science of Monetary Policy: A New Keynesian Perspective," Journal of Economic Literature, 37(4), 1661-1707.

Cover, J. P. (1992): "Asymmetric Effects of Positive and Negative Money-Supply Shocks," The Quarterly Journal of Economics, 107(4), 1261-82.

Davig, T., And E. M. Leeper (2007): "Generalizing the Taylor Principle," American Economic Review, 97(3), 607-635.

(2008): "Endogenous Monetary Policy Regime Change," in NBER International Seminar on Macroeconomics 2006, NBER Chapters, pp. 345-391. National Bureau of Economic Research, Inc.

Devereux, M. B., And H. E. Siu (2007): "State Dependent Pricing And Business Cycle Asymmetries," International Economic Review, 48(1), 281-310.

Dixit, A. K. (1989): "Entry and Exit Decisions under Uncertainty," Journal of Political Economy, 97(3), 620-38.

Dufrenot, G., V. Mignon, and A. Peguin-Feissolle (2004): "Business cycles asymmetry and monetary policy: a further investigation using MRSTAR models," Economic Modelling, 21(1), 37-71.

Eusepi, S., And B. Preston (2009): "Labor Supply Heterogeneity and Macroeconomic Comovement," NBER Working Papers 15561, National Bureau of Economic Research, Inc.

FALK, B. (1986): "Further Evidence on the Asymmetric Behavior of Economic Time Series over the Business Cycle," Journal of Political Economy, 94(5), 1096-1109.

Farmer, R. E. A., D. F. Waggoner, and T. Zha (2008): "Minimal state variable solutions to Markov-switching rational expectations models," Working Paper 2008-23, Federal Reserve Bank of Atlanta.

(2009): "Understanding Markov-switching rational expectations models," Journal of Economic Theory, 144(5), 1849-1867.

Florio, A. (2004): "The Asymmetric Effects of Monetary Policy," Journal of Economic Surveys, $18,409-426$. 
Frederick, S., and G. Loewenstein (1999): "Hedonic Adaptation," in Well-Being: The Foundations of Hedonic Psychology, ed. by D. Kahneman, E. Diener, and N. Schwarz, vol. 1, chap. 2, pp. 302-329. Russell Sage Foundation Press, New York.

Friedman, M., And A. J. Schwartz (1963): A Monetary History of the United States, 18671960. Princeton University Press, Princeton NJ, for NBER.

Geanakoplos, J., D. Pearce, and E. Stacchetti (1989): "Psychological games and sequential rationality," Games and Economic Behavior, 1(1), 60-79.

Graham, F. D. (1930): Exchange, Prices and Production in Hyper-inflation: Germany, 192023. Princeton University Press, Princeton NJ.

Hall, P. (1992): The Bootstrap and Edgeworth Expansion. Springer-Verlag, New York.

Hansen, G. D. (1985): "Indivisible labor and the business cycle," Journal of Monetary Economics, 16(3), 309-327.

Heidhues, P., and B. Köszegi (2005): "The Impact of Consumer Loss Aversion on Pricing," CEPR Discussion Papers 4849, C.E.P.R. Discussion Papers.

Hiriart-Urruty, J.-B., and C. Lemaréchal (2001): Fundamentals of Convex Analysis. Springer, Berlin.

Kahneman, D., and A. Tversky (1979): "Prospect Theory: An Analysis of Decision under Risk," Econometrica, 47(2), 263-91.

Karras, G. (1996): "Are the Output Effects of Monetary Policy Asymmetric? Evidence from a Sample of European Countries," Oxford Bulletin of Economics and Statistics, 58(2), 267-78.

Keynes, J. M. (1936): The General Theory of Employment, Interest and Money. Macmillan, London.

Kimball, M. S., and M. D. Shapiro (2008): "Labor Supply: Are the Income and Substitution Effects Both Large or Both Small?," NBER Working Papers 14208, National Bureau of Economic Research, Inc.

Koop, G., M. H. Pesaran, and S. M. Potter (1996): "Impulse response analysis in nonlinear multivariate models," Journal of Econometrics, 74(1), 119-147.

Koszegi, B., and M. Rabin (2006): "A Model of Reference-Dependent Preferences," The Quarterly Journal of Economics, 121(4), 1133-1165.

(2009): "Reference-Dependent Consumption Plans," American Economic Review, 99(3), 909-36.

Köbberling, V., And P. P. Wakker (2005): "An index of loss aversion," Journal of Economic Theory, 122(1), 119-131. 
Laxton, D., D. Rose, and D. Tambakis (1999): "The U.S. Phillips curve: The case for asymmetry," Journal of Economic Dynamics and Control, 23(9-10), 1459-1485.

Leeper, E. M., And T. Zha (2003): "Modest policy interventions," Journal of Monetary Economics, 50(8), 1673-1700.

Liu, Z., D. Waggoner, and T. Zha (2009): "Asymmetric Expectation Effects of Regime Shifts in Monetary Policy," Review of Economic Dynamics, 12(2), 284-303.

Liu, Z., D. F. Waggoner, and T. Zha (2010): "Sources Of Macroeconomic Fluctuations: A Regime-Switching Dsge Approach," Emory Economics 1002, Department of Economics, Emory University (Atlanta).

Lo, M. C., And J. Piger (2005): "Is the Response of Output to Monetary Policy Asymmetric? Evidence from a Regime-Switching Coefficients Model," Journal of Money, Credit and Banking, 37(5), 865-86.

McCallum, B. T. (2001): "Should Monetary Policy Respond Strongly to Output Gaps?," American Economic Review, 91(2), 258-262.

MCKAY, A., And R. REIS (2008): "The brevity and violence of contractions and expansions," Journal of Monetary Economics, 55(4), 738-751.

Mitchell, W. C. (1927): Business Cycles: The Problem and its Setting. National Bureau of Economic Research, New York.

Olivei, G., And S. Tenreyro (2007): "The Timing of Monetary Policy Shocks," American Economic Review, 97(3), 636-663.

Peersman, G., and F. Smets (2005): "The Industry Effects of Monetary Policy in the Euro Area," Economic Journal, 115(503), 319-342.

Ravn, M. O., and M. Sola (2004): "Asymmetric effects of monetary policy in the United States," Review, Federal Reserve Bank of St. Louis, (Sep), 41-60.

Rogerson, R. (1988): "Indivisible labor, lotteries and equilibrium," Journal of Monetary Economics, 21(1), 3-16.

Rosenblatt-Wisch, R. (2008): "Loss aversion in aggregate macroeconomic time series," European Economic Review, 52(7), 1140-1159.

Rotemberg, J. J., and M. Woodford (1998): "An Optimization-Based Econometric Framework for the Evaluation of Monetary Policy: Expanded Version," NBER Technical Working Papers 0233, National Bureau of Economic Research, Inc.

Senda, T. (2001): "Asymmetric Effects of Money Supply Shocks and Trend Inflation," Journal of Money, Credit and Banking, 33(1), 65-89.

Sims, C. A. (1992): "Interpreting the macroeconomic time series facts : The effects of monetary policy," European Economic Review, 36(5), 975-1000. 
Sims, C. A. (2002): "Solving Linear Rational Expectations Models," Computational Economics, 20(1-2), 1-20.

Smets, F., And R. Wouters (2007): "Shocks and Frictions in US Business Cycles: A Bayesian DSGE Approach," American Economic Review, 97(3), 586-606.

Thaler, R. H., A. Tversky, D. Kahneman, and A. Schwartz (1997): "The Effect of Myopia and Loss Aversion on Risk Taking: An Experimental Test," The Quarterly Journal of Economics, 112(2), 647-61.

Thома, M. A. (1994): "Subsample instability and asymmetries in money-income causality," Journal of Econometrics, 64(1-2), 279-306.

Tversky, A., And D. Kahneman (1991): "Loss Aversion in Riskless Choice: A ReferenceDependent Model," The Quarterly Journal of Economics, 106(4), 1039-61.

(1992): "Advances in Prospect Theory: Cumulative Representation of Uncertainty," Journal of Risk and Uncertainty, 5(4), 297-323.

Veronesi, P. (2004): "Belief-dependent Utilities, Aversion to State-Uncertainty and Asset Prices," CRSP working papers 529, Center for Research in Security Prices, Graduate School of Business, University of Chicago.

Wakker, P., And A. Tversky (1993): "An Axiomatization of Cumulative Prospect Theory," Journal of Risk and Uncertainty, 7(2), 147-75.

Weise, C. L. (1999): "The Asymmetric Effects of Monetary Policy: A Nonlinear Vector Autoregression Approach," Journal of Money, Credit and Banking, 31(1), 85-108.

YARIV, L. (2002): "I'll See It When I Believe It - A Simple Model of Cognitive Consistency," Cowles Foundation Discussion Papers 1352, Cowles Foundation, Yale University.

Yogo, M. (2008): "Asset Prices Under Habit Formation and Reference-Dependent Preferences," Journal of Business \& Economic Statistics, 26, 131-143.

Zarnowitz, V. (1992): Business Cycles: Theory, History, Indicators, and Forecasts, Chicago. University of Chicago Press. 


\section{Figures}

Figure 1: NBER recession bands and "contraction" bands derived from the month-to-month rate of growth of the $\mathrm{CBO}$ output gap series.
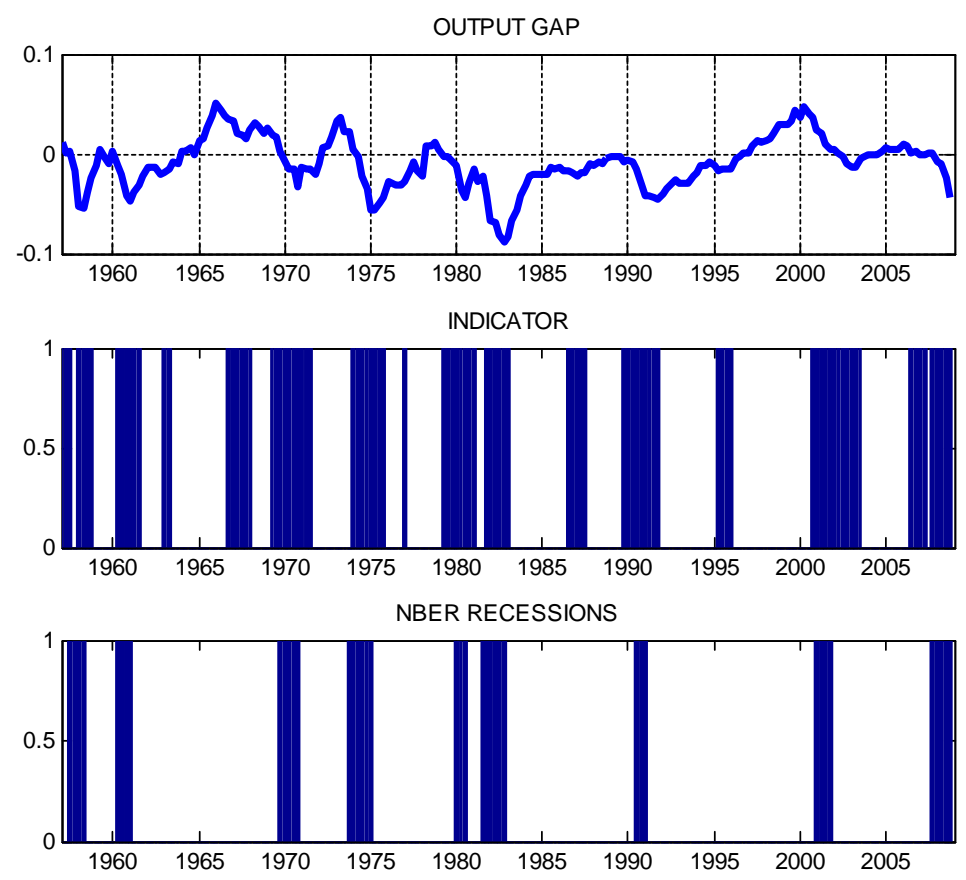
Figure 2. Impulse responses to a monetary policy shock for expansionary and contractionary phases of the U.S. business cycle.

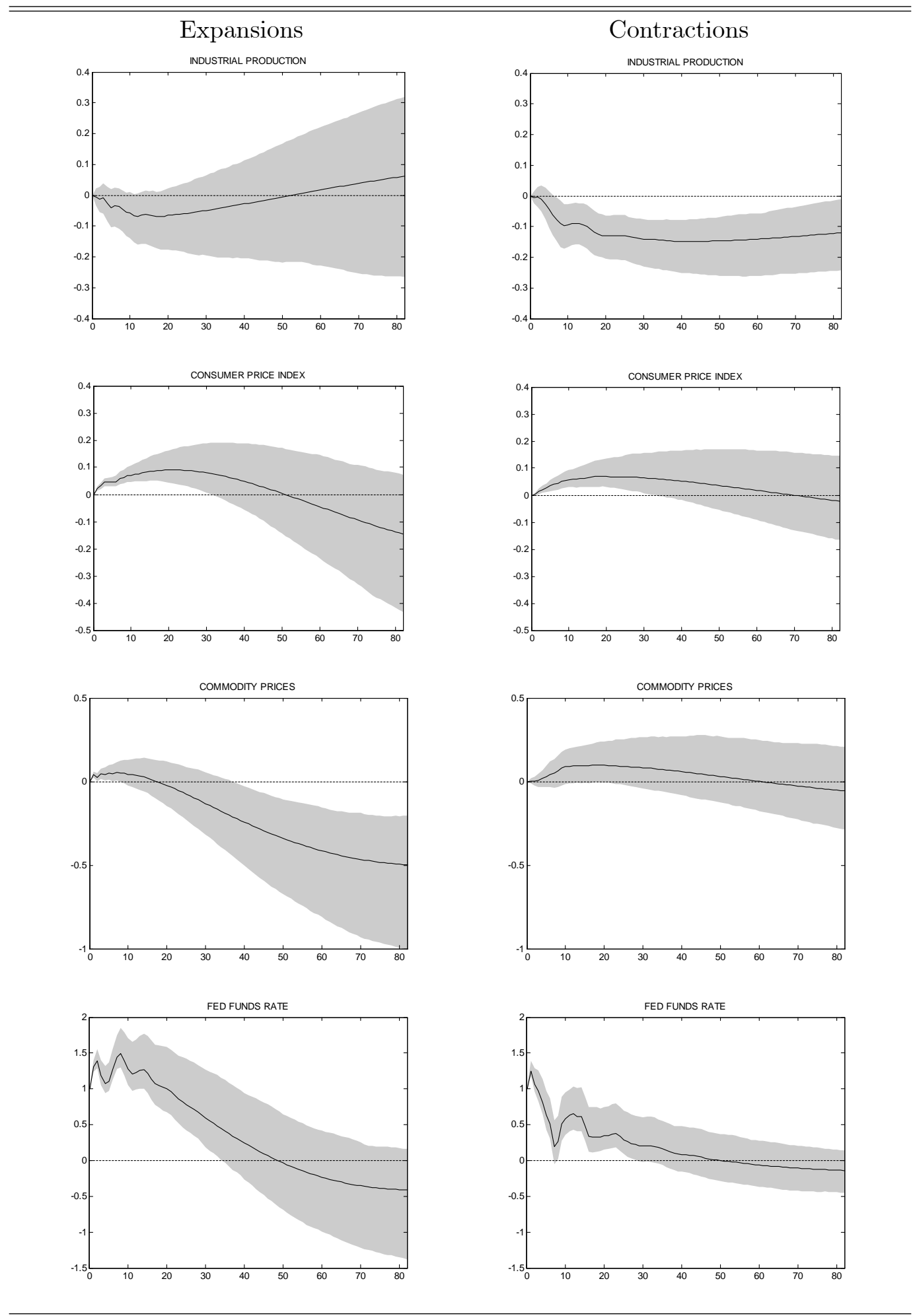

Notes: the figure also displays the $90 \%$ confidence bands (the shaded areas) based on the other percentile bootstrap method (Hall, 1992). 

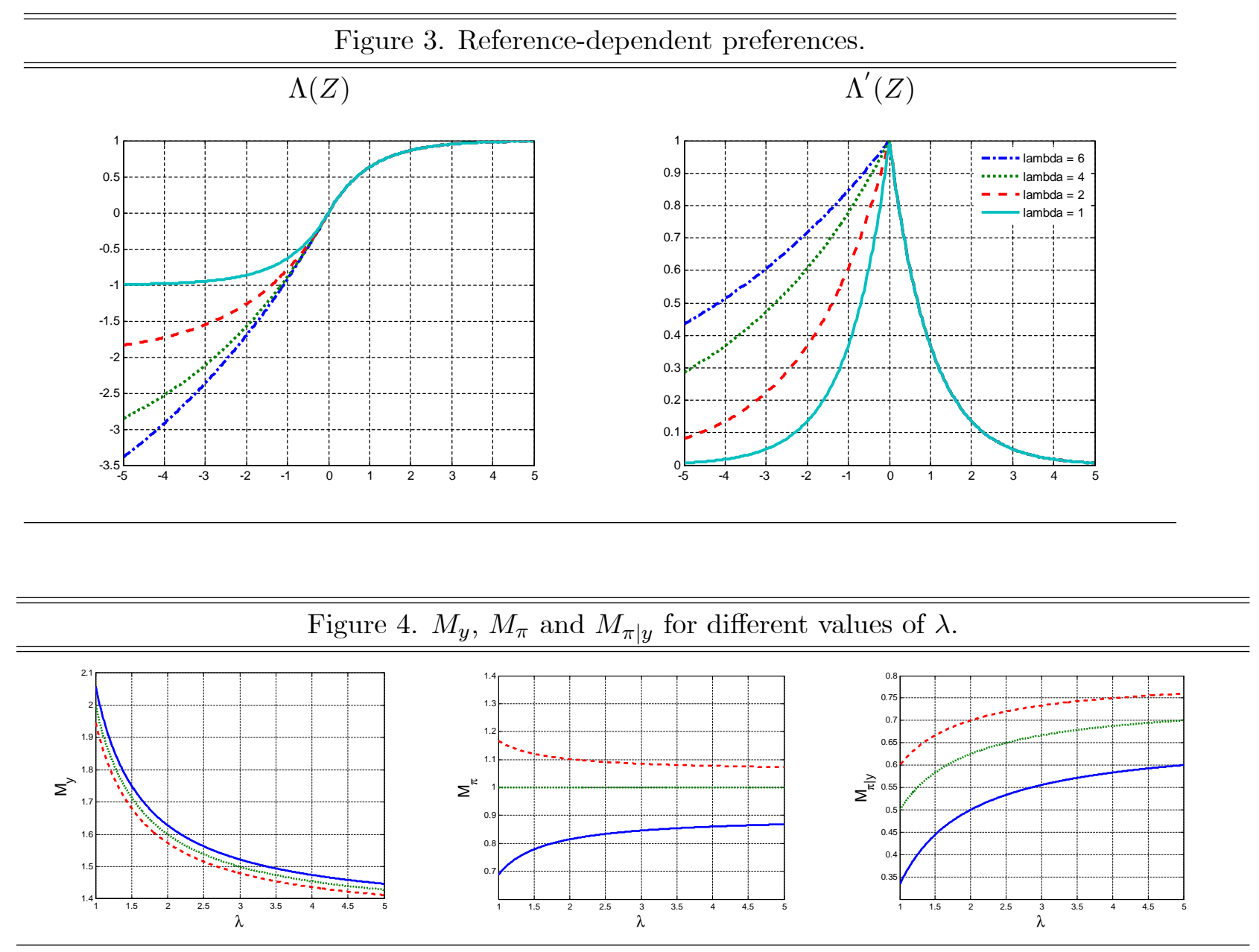

Notes. We use the continuos line for $\eta=0$, while the dotted and dashed lines refer to $\eta=0.5$ and $\eta=1$, respectively. 
Figure 5. Impulse responses to a monetary policy shock (MS-DSGE model).

\section{Forward Looking Model}
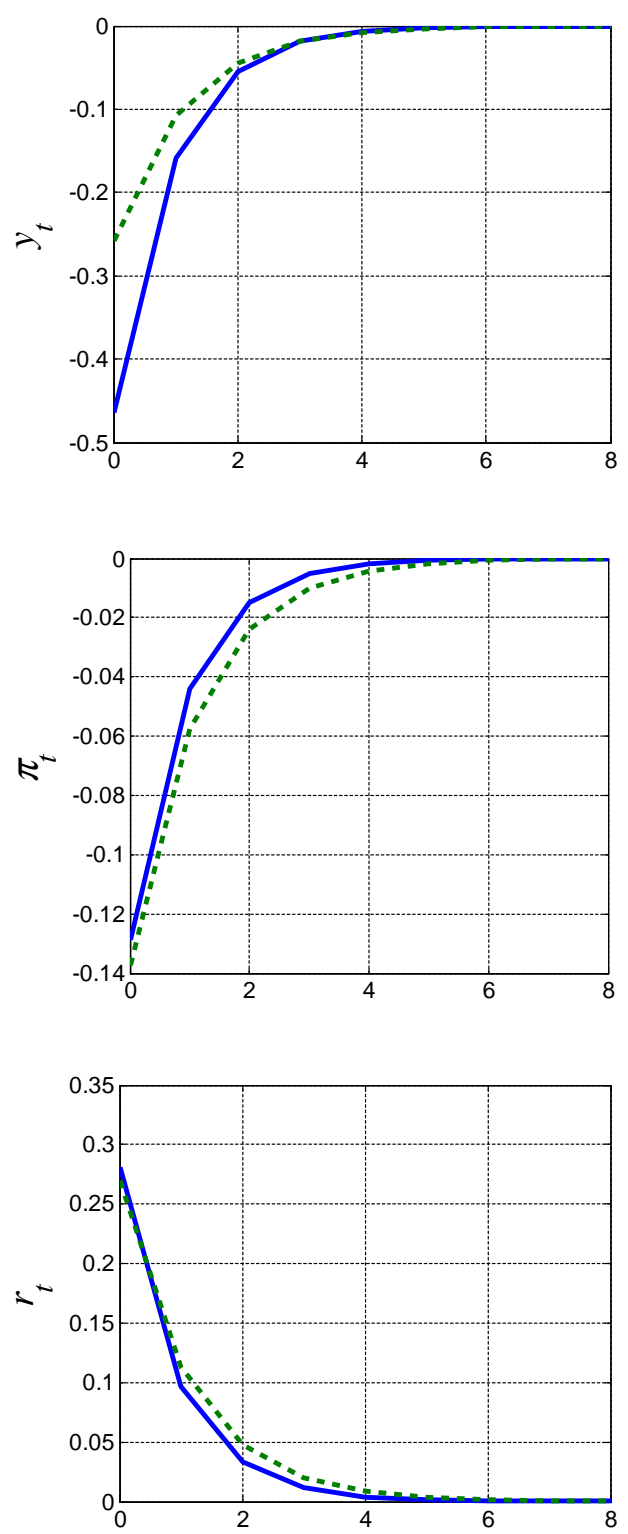

\section{Baseline Calibration}
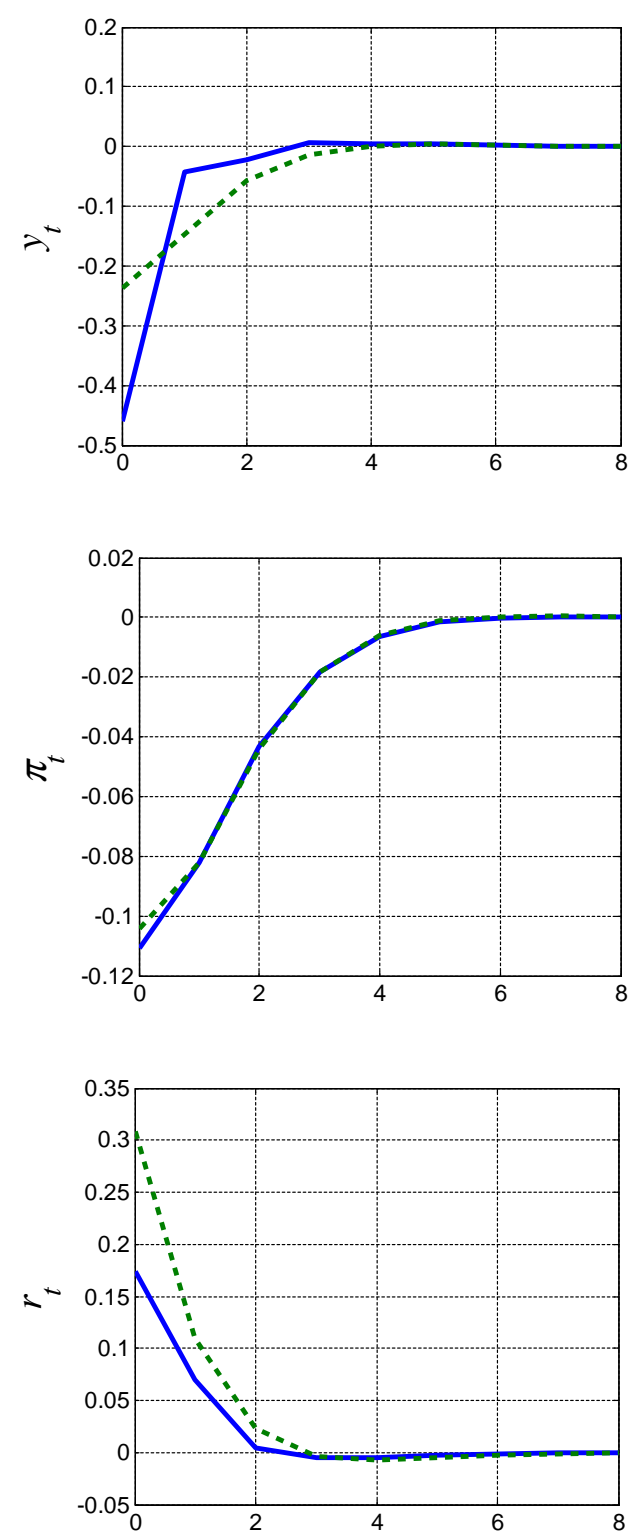

Notes. The responses are calculated by Montecarlo methods, using a procedure similar to that embodied in the generalized impulse response function (Koop et al., 1996; Liu et al., 2009). The dashed (continuous) line corresponds to the responses under the expansionary (contractionary) state. The forward looking model refers to the configuration with forward looking IS and NKPC and an instrumental rule with interest rate smoothing. 
Figure 6. Efficient policy frontiers.

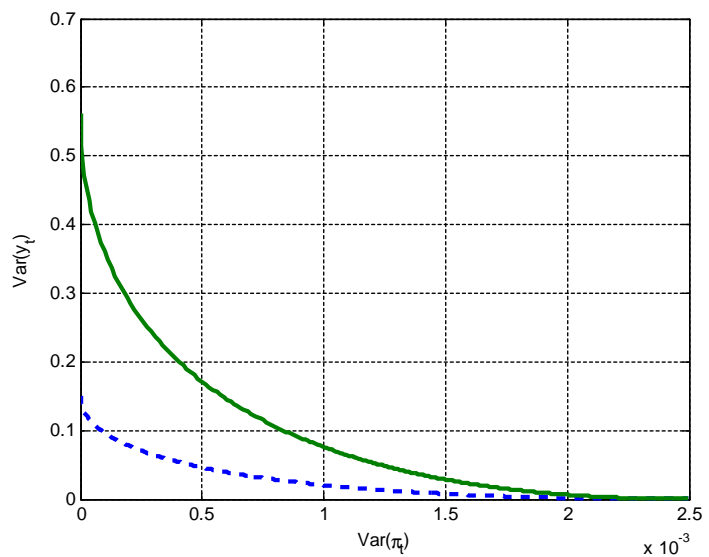

Notes. The dashed (continuous) line corresponds to the locus of different combinations of $\sigma_{\pi}$ and $\sigma_{y}$, for varying values of $\varrho$ in the expansionary (contractionary) state. 


\section{APPENDIX A: Log-linear State-Dependent System.}

\section{The IS Curve}

We start by reporting the Euler equation consistent with each of the four cases:

$$
\beta E_{t}\left\{\frac{R_{t}}{1+\pi_{t+1}}\right\}=\left\{\begin{array}{cc}
E_{t}\left\{\frac{\alpha C_{i t}^{-1}+(1-\alpha) C_{i t}^{-1} \exp \left(-\theta \ln H_{i t}\right)}{\alpha C_{i t+1}^{-1}+(1-\alpha) C_{i t+1}^{-1} \exp \left(-\theta \ln H_{i t+1}\right)}\right\} & \text { iff }\left\{s_{i t}=A\right\} \cap\left\{s_{i t+1}=A\right\} \\
E_{t}\left\{\frac{\alpha C_{i t}^{-1}+(1-\alpha) C_{i t}^{-1} \exp \left(-\theta \ln H_{i t}\right)}{\alpha C_{i t+1}^{-1}+(1-\alpha) C_{i t+1}^{-1} \exp \left(\frac{\theta}{\lambda} \ln H_{i t+1}\right)}\right\} & \text { iff }\left\{s_{i t}=A\right\} \cap\left\{s_{i t+1}=B\right\} \\
E_{t}\left\{\frac{\alpha C_{i t}^{-1}+(1-\alpha) C_{i t}^{-1} \exp \left(\frac{\theta}{\lambda} \ln H_{i t}\right)}{\alpha C_{i t+1}^{-1}+(1-\alpha) C_{i t+1}^{-1} \exp \left(-\theta \ln H_{i t+1}\right)}\right\} & \text { iff }\left\{s_{i t}=B\right\} \cap\left\{s_{i t+1}=A\right\} \\
E_{t}\left\{\frac{\alpha C_{i t}^{-1}+(1-\alpha) C_{i t}^{-1} \exp \left(\frac{\theta}{\lambda} \ln H_{i t}\right)}{\alpha C_{i t+1}^{-1}+(1-\alpha) C_{i t+1}^{-1} \exp \left(\frac{\theta}{\lambda} \ln H_{i t+1}\right)}\right\} & \text { iff }\left\{s_{i t}=B\right\} \cap\left\{s_{i t+1}=B\right\}
\end{array}\right.
$$

where $H_{i t}=C_{i t} / X_{i t}$. After log-linearizing around $H=1$ we obtain the following statedependent system of linearized IS curves:

$$
y_{t}=\left\{\begin{array}{ll}
\frac{1+(1-\alpha) \theta}{1+(1-\alpha)(1+\gamma) \theta} E_{t} y_{t+1}+\frac{(1-\alpha) \gamma \theta}{1+(1-\alpha)(1+\gamma) \theta} y_{t-1}-\frac{i_{t}-E_{t} \pi_{t+1}}{1+(1-\alpha)(1+\gamma) \theta} \quad \text { iff } \xi_{t}=\{A, A\} \\
\frac{1-(1-\alpha) \frac{\theta}{\lambda}}{1+(1-\alpha) \theta\left(1-\frac{\gamma}{\lambda}\right)} E_{t} y_{t+1}+\frac{(1-\alpha) \theta \gamma}{1+(1-\alpha) \theta\left(1-\frac{\gamma}{\lambda}\right)} y_{t-1}-\frac{i_{t}-E_{t} \pi_{t+1}}{1+(1-\alpha) \theta\left(1-\frac{\gamma}{\lambda}\right)} & \text { iff } \xi_{t}=\{A, B\} \\
\frac{1+(1-\alpha) \theta}{1-(1-\alpha) \theta\left(\frac{1}{\lambda}-\gamma\right)} E_{t} y_{t+1}-\frac{(1-\alpha) \frac{\theta}{\lambda} \gamma}{1-(1-\alpha) \theta\left(\frac{1}{\lambda}-\gamma\right)} y_{t-1}-\frac{i_{t}-E_{t} \pi_{t+1}}{1-(1-\alpha) \theta\left(\frac{1}{\lambda}-\gamma\right)} & \text { iff } \xi_{t}=\{B, A\} \\
\frac{1-(1-\alpha) \frac{\theta}{\lambda}}{1-(1-\alpha)(1+\gamma) \frac{\theta}{\lambda}} E_{t} y_{t+1}-\frac{(1-\alpha) \frac{\theta}{\lambda}}{1-(1-\alpha)(1+\gamma) \frac{\theta}{\lambda}} y_{t-1}-\frac{i_{t}-E_{t} \pi_{t+1}}{1-(1-\alpha)(1+\gamma) \frac{\theta}{\lambda}} & \text { iff } \xi_{t}=\{B, B\}
\end{array},\right.
$$

where we have aggregated across individuals (imposing homogeneity) and used the goods market clearing condition, $Y_{t}=C_{t}$.

When it comes to linearize the model economy in the neighborhood of $C / X=1$, it is important to note that $\Lambda^{\prime}(Z)$ presents an ordinary double point at $Z=0$. As such, $\Lambda^{\prime}(Z)$ is not purely differentiable in that point, as also implied by property (i). Therefore, standard linear approximation techniques such as the Taylor expansion do not immediately apply in this case. However, we can resort to a first-order approximation of $\Lambda^{\prime}(Z)$ by computing an affine global underestimator, thus determining the subgradients of the marginal utility function at $Z=0$. A subgradient determines a support hyperplane to the graph of the function under scrutiny. In such a case the corresponding subdifferential is a direct generalization of the differentiable case. For a convex and non necessarily differentiable function $f: \mathbb{R}^{n} \rightarrow \mathbb{R}$, the subdifferential at $x_{0}$ is defined as $\partial f\left(x_{0}\right)=\left\{g \in \mathbb{R}: \quad f(x) \geq f\left(x_{0}\right)+\left\langle g, x-x_{0}\right\rangle\right\}$. Thus, $g \in f\left(x_{0}\right)$ is subgradient in $x_{0} \cdot{ }^{30}$ In our case it is straightforward to notice that at $Z=0$ there will be a single subgradient

\footnotetext{
${ }^{30}$ See Hiriart-Urruty and Lemaréchal (2001).
} 
for each branch of the function under scrutiny. To gain intuition on this, we can re-write the marginal utility as $\Lambda^{\prime}(Z)=\min \left\{\Lambda_{A}^{\prime}(Z), \Lambda_{B}^{\prime}(Z)\right\}$ for $Z \in \mathbb{R}$, where $\Lambda_{A}^{\prime}(Z)$ and $\Lambda_{B}^{\prime}(Z)$ are the functions that encompass the arms of marginal utility corresponding to $Z>0$ and $Z<0$, respectively. These functions are both convex. It is also easy to see that $\Lambda_{B}^{\prime}(Z)>\Lambda_{A}^{\prime}(Z)$ for $Z \in \mathbb{R}^{+}$and $\Lambda_{B}^{\prime}(Z)<\Lambda_{A}^{\prime}(Z)$ for $Z \in \mathbb{R}^{-}$. Hence, our approach corresponds to a piece-wise linear approximation in the neighborhood of $Z=0$. Notice also that assuming a smooth gainloss function $\Lambda(Z)$ at $Z=0$ allows us to obtain a continuous first derivative function, which improves the approximation around the point $Z=0$, compared to what would happen, say, with a linear gain-loss function, which implies a discontinuity at $\Lambda^{\prime}(0)$. This is done by constraining the coefficient in the exponential part of the left-hand branch of the gain loss function to be $\theta / \lambda$ rather than $\theta$. This assumption also allows us to implicitly consider loss aversion under its strong formulation, as explained by Wakker and Tversky (1993) and Köbberling and Wakker (2005), meaning that $\Lambda^{\prime}(-Z)>\Lambda^{\prime}(Z), \forall Z>0$.

\section{Inflation Dynamics}

After applying some trivial algebra we retrieve a log-linearized expression for the real marginal cost:

$$
r m c_{t}=\left\{\begin{array}{cc}
(\eta+1+(1-\alpha) \theta) c_{t}-(1-\alpha) \theta \gamma c_{t-1}-(1+\eta) z_{t} & \text { iff } s_{t}=A \\
\left(\eta+1-(1-\alpha) \frac{\theta}{\lambda}\right) c_{t}+(1-\alpha) \frac{\theta}{\lambda} \gamma c_{t-1}-(1+\eta) z_{t} & \text { otherwise }
\end{array} .\right.
$$

Thus the piece-wise linear NKPC reads as:

$\pi_{t}=\varphi^{f} E_{t} \pi_{t+1}+\varphi^{b} \pi_{t-1}+\kappa\left\{\begin{array}{ll}(\eta+1+(1-\alpha) \theta) y_{t}-(1-\alpha) \theta \gamma y_{t-1}-(1+\eta) z_{t} & \text { iff } s_{t}=A \\ \left(\eta+1-(1-\alpha) \frac{\theta}{\lambda}\right) y_{t}+(1-\alpha) \frac{\theta}{\lambda} \gamma y_{t-1}-(1+\eta) z_{t} & \text { otherwise }\end{array}\right.$, where:

$$
\begin{aligned}
\varphi^{f} & =\frac{\beta}{1+\beta \vartheta}, \\
\varphi^{b} & =\frac{\vartheta}{1+\beta \vartheta}, \\
\kappa & =\frac{(1-\omega \beta)(1-\omega)}{\omega(1+\beta \vartheta)} .
\end{aligned}
$$

\section{APPENDIX B: Setting the Model into the Form of Farmer, Wag- goner and Zha $(2008,2009)$.}

We now can write the model reported above into canonical form in the following compact form:

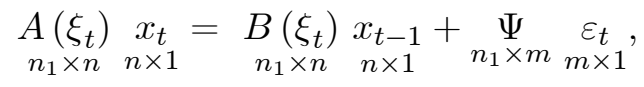


where

$$
x_{t}=\left[y_{t}, \pi_{t}, i_{t}, z_{t}, u_{t}, \mu_{t}, E_{t} y_{t+1}, E_{t} \pi_{t+1}\right]^{\prime},
$$

is the vector of variables to solve for and $u_{t}$ denotes a log-stationary cost-push shock. Also,

$$
\varepsilon_{t}=\left[\varepsilon_{t}^{z}, \varepsilon_{t}^{u}, \varepsilon_{t}^{\mu}\right]^{\prime},
$$

is a vector of fundamental shocks. The following notation applies:

$$
\begin{aligned}
n & =\text { number of all variables for each regime }(8), \\
m & =\text { number of fundamental shocks }(3), \\
n_{1} & =\text { number of equations in each regime }(4) .
\end{aligned}
$$

After writing the model in the following form we can report the matrices $A_{\xi_{t}}$ and $B_{\xi_{t}}$ containing parameters that are possibly regime dependent:

$$
\begin{aligned}
y_{t} & =\phi_{1}\left(\xi_{t}\right) E_{t} y_{t+1}+\phi_{2}\left(\xi_{t}\right) y_{t-1}-\phi_{3}\left(\xi_{t}\right)\left(i_{t}-E_{t} \pi_{t+1}\right), \\
\pi_{t} & =\varphi^{f} E_{t} \pi_{t+1}+\varphi^{b} \pi_{t-1}+\psi_{1}\left(\xi_{t}\right) y_{t}+\psi_{2}\left(\xi_{t}\right) y_{t-1}-(1+\eta) \kappa z_{t}+u_{t}, \\
i_{t} & =r_{R} i_{t-1}+\left(1-r_{R}\right) r_{\Pi} \pi_{t}+\left(1-r_{R}\right) r_{Y} y_{t}+\mu_{t},
\end{aligned}
$$

where:

$$
\begin{gathered}
\phi_{1}\left(\xi_{t}=1\right)=\frac{1+(1-\alpha) \theta}{1+(1-\alpha)(1+\gamma) \theta} ; \quad \phi_{1}\left(\xi_{t}=2\right)=\frac{1-(1-\alpha) \frac{\theta}{\lambda}}{1+(1-\alpha) \theta\left(1-\frac{\gamma}{\lambda}\right)}, \\
\phi_{1}\left(\xi_{t}=3\right)=\frac{1+(1-\alpha) \theta}{1-(1-\alpha) \theta\left(\frac{1}{\lambda}-\gamma\right)} ; \quad \phi_{1}\left(\xi_{t}=4\right)=\frac{1-(1-\alpha) \frac{\theta}{\lambda}}{1-(1-\alpha)(1+\gamma) \frac{\theta}{\lambda}}, \\
\phi_{2}\left(\xi_{t}=1\right)=\frac{(1-\alpha) \gamma \theta}{1+(1-\alpha)(1+\gamma) \theta} ; \quad \phi_{2}\left(\xi_{t}=2\right)=\frac{(1-\alpha) \theta \gamma}{1+(1-\alpha) \theta\left(1-\frac{\gamma}{\lambda}\right)}, \\
\phi_{2}\left(\xi_{t}=3\right)=-\frac{(1-\alpha) \frac{\theta}{\lambda} \gamma}{1-(1-\alpha) \theta\left(\frac{1}{\lambda}-\gamma\right)} ; \quad \phi_{2}\left(\xi_{t}=4\right)=-\frac{(1-\alpha) \gamma \frac{\theta}{\lambda}}{1-(1-\alpha)(1+\gamma) \frac{\theta}{\lambda}}, \\
\phi_{3}\left(\xi_{t}=1\right)=\frac{1}{1+(1-\alpha)(1+\gamma) \theta} ; \quad \phi_{3}\left(\xi_{t}=2\right)=\frac{1}{1+(1-\alpha) \theta\left(1-\frac{\gamma}{\lambda}\right)}, \\
\phi_{3}\left(\xi_{t}=3\right)=\frac{1}{1-(1-\alpha) \theta\left(\frac{1}{\lambda}-\gamma\right)} ; \quad \phi_{3}\left(\xi_{t}=4\right)=\frac{1}{1-(1-\alpha)(1+\gamma) \frac{\theta}{\lambda}}, \\
\psi_{1}\left(\xi_{t}=1\right)=\psi_{1}\left(\xi_{t}=2\right)=\kappa(\eta+1+(1-\alpha) \theta), \\
\psi_{1}\left(\xi_{t}=3\right)=\psi_{1}\left(\xi_{t}=4\right)=\kappa\left(\eta+1-(1-\alpha) \frac{\theta}{\lambda}\right),
\end{gathered}
$$




$$
\begin{aligned}
& \psi_{2}\left(\xi_{t}=1\right)=\psi_{2}\left(\xi_{t}=2\right)=-(1-\alpha) \theta \gamma \kappa \\
& \psi_{2}\left(\xi_{t}=3\right)=\psi_{2}\left(\xi_{t}=4\right)=(1-\alpha) \frac{\theta}{\lambda} \gamma \kappa
\end{aligned}
$$

Consequently:

$$
\begin{aligned}
& \underset{6 \times 8}{A\left(\xi_{t}\right)}=\left[\begin{array}{cccccccc}
1 & 0 & \phi_{3}\left(\xi_{t}\right) & 0 & 0 & 0 & -\phi_{1}\left(\xi_{t}\right) & -\phi_{3}\left(\xi_{t}\right) \\
-\psi_{1}\left(\xi_{t}\right) & 1 & 0 & (1+\eta) \kappa & -1 & 0 & 0 & -\varphi^{f} \\
-\left(1-r_{R}\right) r_{Y} & -\left(1-r_{R}\right) r_{\Pi} & 1 & 0 & 0 & -1 & 0 & 0 \\
0 & 0 & 0 & 1 & 0 & 0 & 0 & 0 \\
0 & 0 & 0 & 0 & 1 & 0 & 0 & 0 \\
0 & 0 & 0 & 0 & 0 & 1 & 0 & 0
\end{array}\right], \\
& \underset{6 \times 8}{B\left(\xi_{t}\right)}=\left[\begin{array}{cccccccc}
\phi_{2}\left(\xi_{t}\right) & 0 & 0 & 0 & 0 & 0 & 0 & 0 \\
\psi_{2}\left(\xi_{t}\right) & \varphi^{b} & 0 & 0 & 0 & 0 & 0 & 0 \\
0 & 0 & r_{R} & 0 & 0 & 0 & 0 & 0 \\
0 & 0 & 0 & \rho^{z} & 0 & 0 & 0 & 0 \\
0 & 0 & 0 & 0 & \rho^{u} & 0 & 0 & 0 \\
0 & 0 & 0 & 0 & 0 & \rho^{\mu} & 0 & 0
\end{array}\right] \\
& \underset{6 \times 3}{\Psi}=\left[\begin{array}{ccc}
0 & 0 & 0 \\
0 & 0 & 0 \\
0 & 0 & 0 \\
\sigma^{z} & 0 & 0 \\
0 & \sigma^{u} & 0 \\
0 & 0 & \sigma^{\mu}
\end{array}\right]
\end{aligned}
$$

Following Farmer, Waggoner, and Zha (2008), we can now expand the system under each regime into an expanded linear system to obtain the MSV solution. 